\title{
(ख)
}

AUTARQUIA ASSOCIADA À UNIVERSIDADE DE SÃO PAULO

Desenvolvimento de uma Metodologia de Avaliação de Medidores Portáteis de Radiação em Altas Taxas de kerma no Ar

Willian Behling Damatto

Dissertação apresentada como parte dos
requisitos para obtenção do Grau de
Mestre em Ciências na Área
de Tecnologia Nuclear-Aplicações

Orientador:

Prof. Dr. Vitor Vivolo

São Paulo

2015 


\title{
INSTITUTO DE PESQUISAS ENERGÉTICAS E NUCLEARES
}

Autarquia associada à Universidade de São Paulo

\section{Desenvolvimento de uma Metodolgia de Avaliação de Medidores Portáteis de Radiação em Altas Taxas de kerma no Ar}

Willian Behling Damatto

\author{
Dissertação apresentada como parte dos \\ requisitos para obtenção do Grau de \\ Mestre em Ciências na Área \\ de Tecnologia Nuclear - Aplicações \\ Orientador: \\ Prof. Dr. Vitor Vivolo
}

Versão Corrigida

São Paulo

2015 
Agradeço primeiramente a Deus, pela certeza de Seu cuidado e companhia.

"Estas coisas vos tenho dito para que tenhais paz em Mim. No mundo, passais por aflições; mas tende bom ânimo; Eu venci o mundo" (Jo 16:33). 
Dedico este Mestrado ao meu primo Victor Damatto Moreira e minha avó Dalva Camillo Damatto que não puderam presenciar este momento. 


\section{AGRADECIMENTOS}

Gostaria de expressar os meus sinceros agradecimentos ao meu orientador e amigo, Dr. Vítor Vívolo, que partilhou seu escasso tempo disponível, entre suas ocupações profissionais, coordenando, sugerindo, comentando e analisando os diversos aspectos do desenvolvimento deste trabalho.

Meus sinceros agradecimentos:

À $\mathrm{Dr}^{\mathrm{a}}$ Maria da Penha A. Potiens, pela sua amizade, pelos comentários, sugestões, apoio no desenvolvimento deste trabalho e pela grande ajuda no meu desenvolvimento acadêmico e profissional.

À Dra ${ }^{\mathrm{a}}$ Sandra Regina Damatto, que me apresentou ao grupo de pesquisa, pela sua grande amizade de tia e amiga, pelos seus comentários, sugestões, e puxões de orelha, pela grande ajuda na correção do meu trabalho e no meu desenvolvimento acadêmico e profissional.

À $\operatorname{Dr}^{\mathrm{a}}$ Linda V. E. Caldas e $\operatorname{Dr}^{\mathrm{a}}$ Leticia L. C. Rodrigues, pela permissão de utilização dos laboratórios do Departamento de Metrologia das Radiações do IPEN, para a realização dos ensaios.

Ao Gelson, Rafhael, Claudinei, Tereza, Ana Maria, e todos os colegas e amigos do Laboratório de Calibração de Instrumentos, pela amizade e horas de descontração.

Aos amigos do IPEN: Brianna Bosch, Eduardo Corrêa, Elaine Wirney, Lilian Kuahara, Camila Trindade, Ladyjane Fontes, Tallyson Alvarenga, Felipe Cintra, Izabel Matos, Mateus Lima, Daniela Groppo, Maíra Yoshizumi, Jonas Silva, Nathalia Almeida e Lucas Rodrigues. 
Ao IPEN, Instituto de Pesquisas Energéticas e Nucleares, pela infra-estrutura oferecida para realização deste trabalho.

À Fundação de Amparo à Pesquisa do Estado de São Paulo (FAPESP), Conselho Nacional de Desenvolvimento Científico e Tecnológico (CNPq), e Ministério da Ciência e Tecnologia (MCT, Projeto: Instituto Nacional de Ciência e Tecnologia (INCT) em Metrologia das Radiações na Medicina), pelo apoio financeiro parcial.

A minha família Luiz, Rosane, Cristina e ao meu amor Marília, que sempre me apoiaram, incentivaram e deram suporte na minha vida acadêmica e profissional. 


\title{
DESENVOLVIMENTO DE UMA METODOLOGIA DE AVALIAÇÃO DE MEDIDORES PORTÁTEIS DE RADIAÇÃO EM ALTAS TAXAS DE KERMA NO AR
}

\author{
Willian Behling Damatto
}

RESUMO

Uma série de testes foi aplicada a medidores portáteis de radiação ionizante para altas taxas de kerma no ar, especificamente medidores do tipo teletector. Estes detectores são do tipo Geiger Müller e são utilizados em rotinas de proteção radiológica em aceleradores, reatores, fontes de alta atividade e ainda em situações de emergência no Brasil, assim como em outros países. Também são encaminhados para calibração no Instituto de Pesquisa Energéticas e Nucleares (IPEN) e foram analisados para estabelecer parâmetros de comportamento destes detectores, especificando as suas sensibilidades e suas características operacionais. Foram realizados testes de variação da leitura dos equipamentos com a tensão da bateria, efeito de geotropismo, dependência energética, dependência angular. Com este testes foi possível determinar as características mais comuns e importantes destes equipamentos permitindo a elaboração de um programa de controle de qualidade. Foram calibrados 17 teletectors durante este trabalho e destes, 10 foram testados. Os testes foram realizados para caracterizar o sis tema gama de irradiação (dosimetria de feixe de radiação) que possui maior atividade e permite testes em medidores do tipo teletectors em uma maior faixa de medição. Desse modo foi feito o aperfeiçoamento do programa de controle de qualidade de medidores portáteis de radiação ionizante para altas taxas de kerma no ar no $\mathrm{LCl}$, oque beneficiou os usuários deste tipo de equipamento, e ainda com medições e calibrações mais consistentes e com melhor controle de qualidade dos processos. 


\title{
DEVELOPMENT OF A METHODOLOGY OF PORTABLE RADIATION METERS AT HIGH RATES OF AIR
}

\author{
Willian Behling Damatto
}

\begin{abstract}
A series of tests was applied to portable survey meters for high rates of kerma in the air, specifically meters type teletector. These detectors are the GeigerMüller type and are used in radioprotection routines in accelerators, nuclear reactors, irradiators systems with high activity sources and even in emergency situations in Brazil, as in other countries. They are also sent for calibration at the Instruments Calibration Laboratory (LCl) at the Institute of Energy and Nuclear Research (IPEN) and were analyzed to establish behavior parameters of these detectors, specifying their sensitivities and their operational characteristics. The reading variation tests were performed with the equipment battery voltage variation, geotropism effect, energy dependence, angular dependence; with these tests was possible to determine the most common and important features of these devices, allowing the development of a quality control program. In this work 17 teletectors were analyzed and ten detectors tested. The tests were performed to characterize the gamma irradiator system (dosimetry of dosimetry beam) which has higher activity and allows test in meters type teletector in a higher measuring range. Thus, it was made the improvement of the quality control program of portable survey meters of high rates of kerma in the air in the $\mathrm{LCl}$, benefiting the users of such equipment and with measurements and calibrations more consistent and better quality control processes.
\end{abstract}




\section{SUMÁRIO}

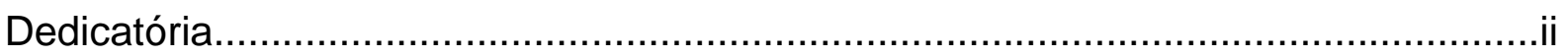

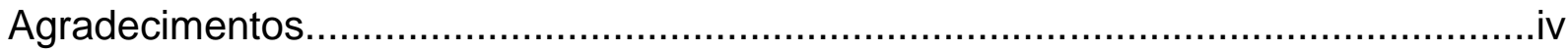

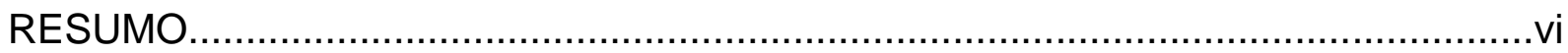

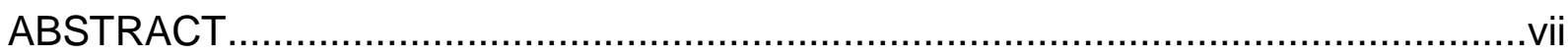

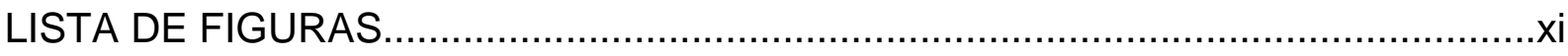

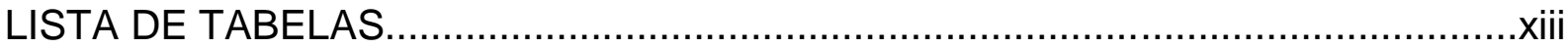

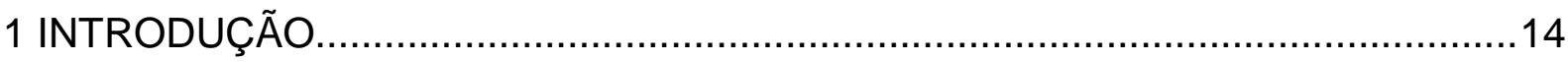

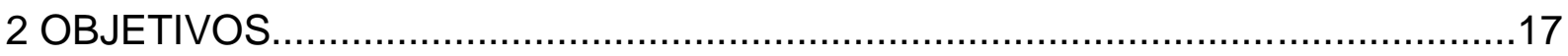

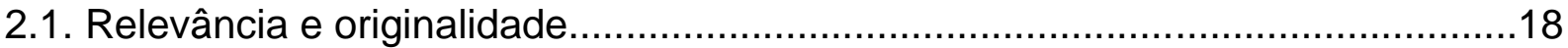

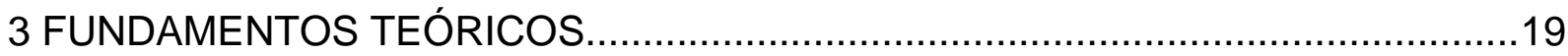

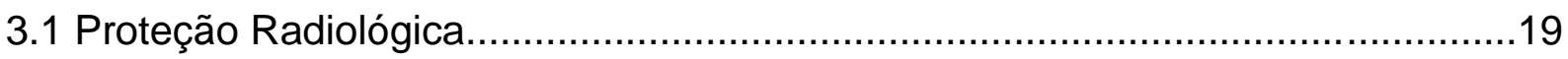

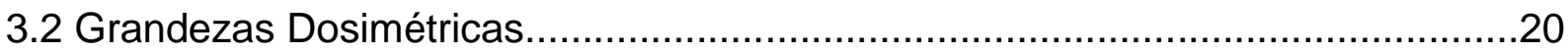

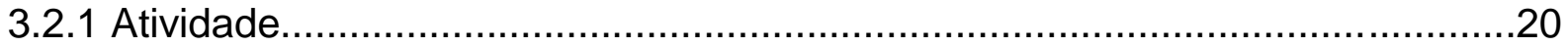

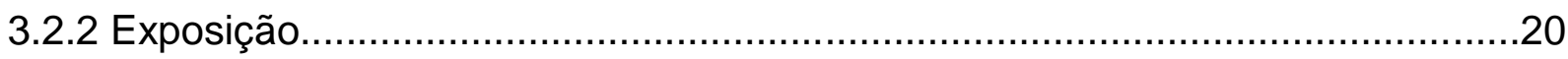

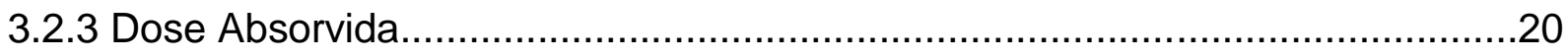

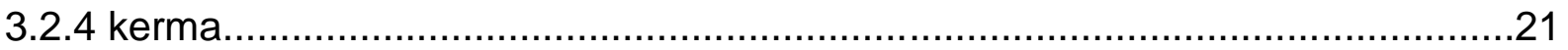

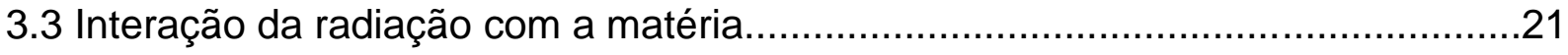

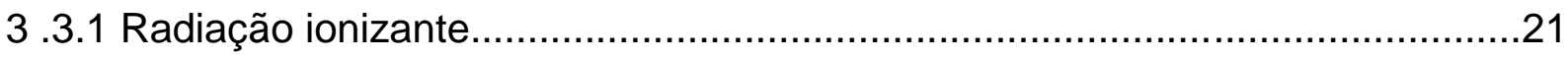

3.3.2 Interação de fótons com a matéria............................................................22

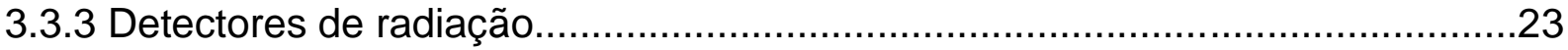

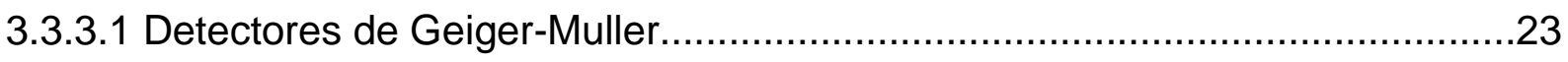

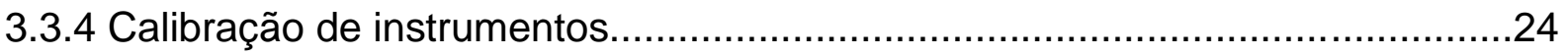




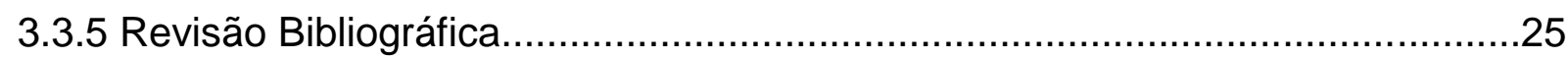

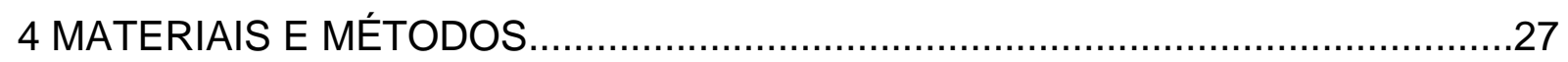

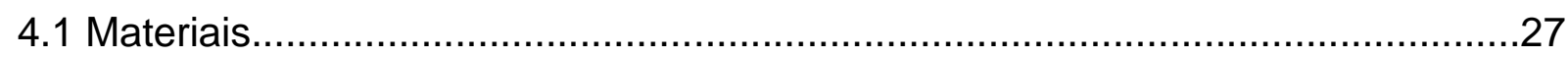

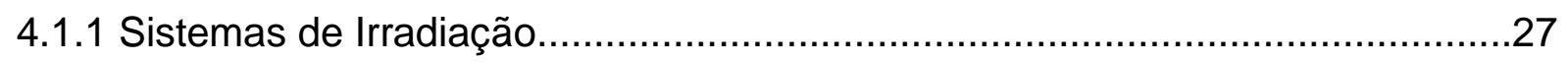

4.1.2 Sistema de Referência de Medida (Nível Radioproteção)................................29

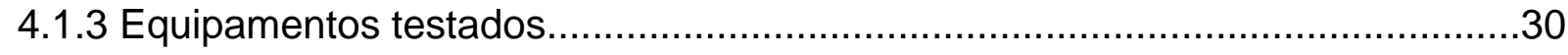

4.1.4 Sistemas Auxiliares e Acessórios Importantes...............................................31

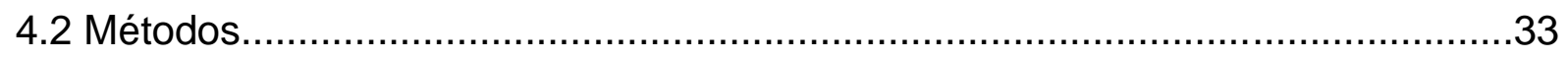

4.2.1 Caracterização dos campos de radiação.....................................................34

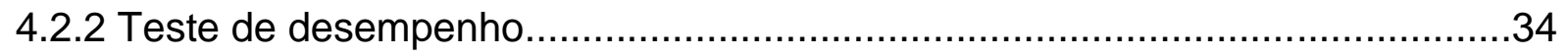

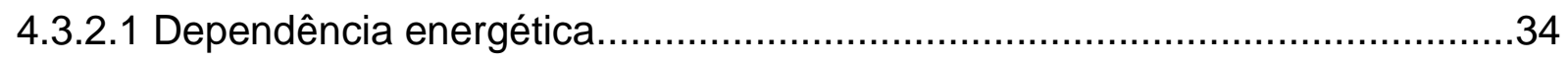

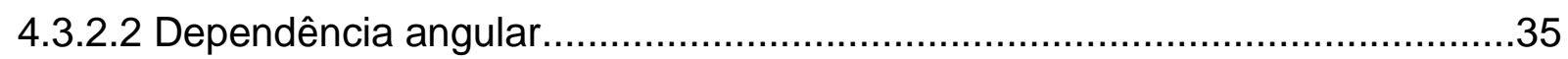

4.3.2.3 Teste de estouro de escala (overload) .....................................................35

3.2.2.4 Verificação do sistema irradiador Hopewell.................................................35

4.2.3 Código de conduta para utilização do teletector..............................................36

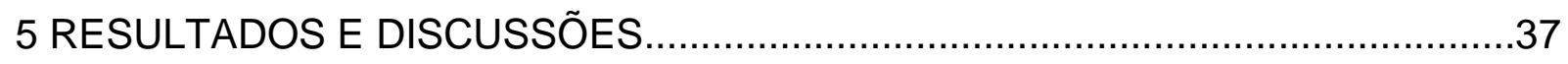

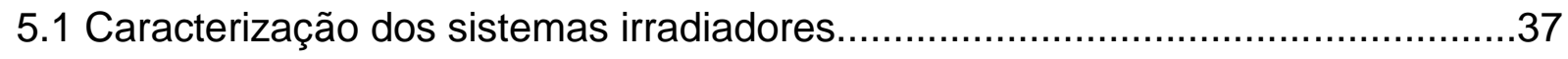

5.1.1 Testes de controle de qualidade do sistema de referência..............................37

5.2 Caracterização do sistema irradiador OB 85/1 ..............................................41

5.3 Homogeneidade do campo de radiação do irradiador OB/85-1 ...........................46

5.4 Caracterização do sistema do Irradiador Caesa-Gammatron...............................48

5.5 Homogeneidade do Campo de Radiação do Irradiador Caesa-Gammatron.........49

5.6 Estudo dos sistemas de deteç̧ão de alta taxa de kerma no ar............................50

5.6.1 Variação da leitura do equipamento com a tensão........................................51 


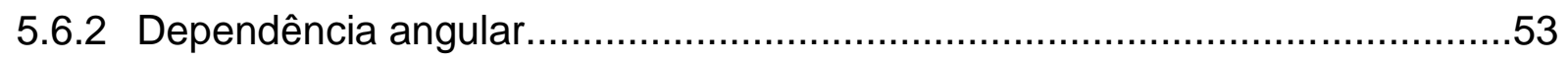

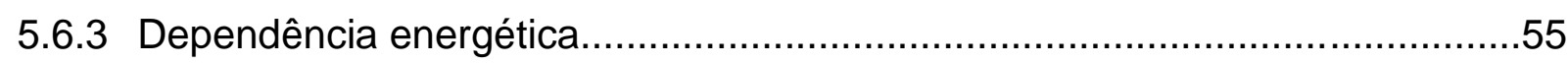

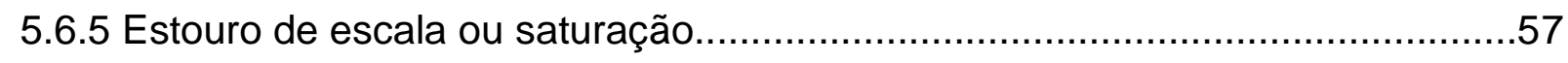

5.6.4 Verificação do novo sistema irradiador gama Hopewell..................................57

5.7 Código de conduta para utilização do Teletector................................................59

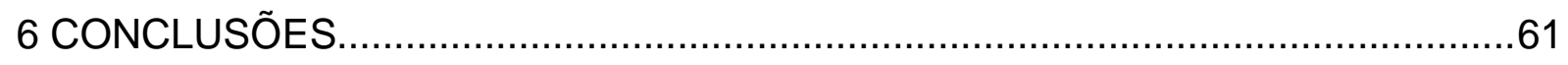

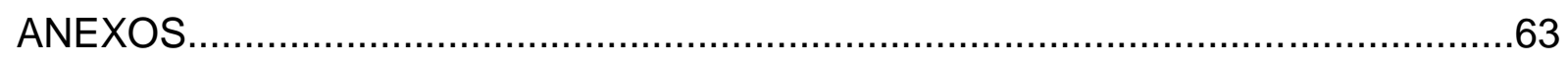

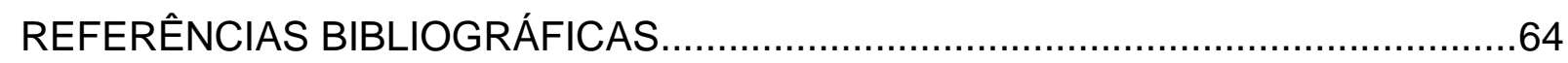




\section{LISTA DE FIGURAS}

Figura 1. Sistema irradiador marca STS, modelo: OB $85 / 1$, com fontes de ${ }^{60} \mathrm{Co}$ e ${ }^{137}$ Cs.

Figura 2. Sistema irradiador marca Caesa-Gammatron com fonte de ${ }^{137} \mathrm{Cs}$

Figura 3. Sistema irradiador marca Hopewell, modelo G10-2-360-E, com fonte ${ }^{137}$ Cs. 28

Figura 4. Eletrômetro marca PTW, modelo UNIDOS. .29

Figura 5. Câmaras de ionização com volume sensível $30 \mathrm{~cm}^{3}$ (modelo 23361).......29

Figura 6. Câmara de ionização com volume sensível $0,30 \mathrm{~cm}^{3}$ (modelo 31013 ).......29

Figura 7. Câmaras de ionização com volume sensível de $1000 \mathrm{~cm}^{3}$. .30

Figura 8. Detector de modelo teletector. 30

Figura 9. Exemplificação da utilização de um Teletector em rotina 31

Figura 10. Sala de controle do laboratório de calibração de monitores portáteis......32

Figura 11. Sala de irradiação do laboratório de calibração de monitores portáteis..32

Figura 12. Sala de controle do laboratório do irradiador Hopewell. .33

Figura 13. Sala de irradiação do irradiador Hopewell 33

Figura 14. Teste de fuga de corrente realizados no conjunto de deteç̧ão padrão do LCI-IPEN 38

Figura 15. Teste de fuga de corrente variando: cabo; detector (câmara de ionização) e eletrômetro. A nomeação do componente no gráfico significa que este foi substituído 39

Figura 16. Teste de fuga de corrente com o conjunto de detecção composto pela câmara de ionização de volume de $30 \mathrm{~cm}^{3}$ e eletrômetro PTW-UNIDOS sem fuga de corrente. .40

Figura 17. Teste de fuga de corrente com o conjunto de detecção composto pela câmara de ionização de volume de $0,3 \mathrm{~cm}^{3}$ e eletrômetro PTW-UNIDOS sem fuga de corrente.

Figura 18. Variação da taxa de kerma no ar com a distância a fonte de radiação ionizante ${ }^{137} \mathrm{Cs}$ sem filtro atenuador ao detector 
Figura 19. Variação da taxa de kerma no ar com a distância com a fonte de radiação ionizante ${ }^{137} \mathrm{Cs}$ com um filtro atenuador ao detector.

Figura 20. Variação da taxa de kerma no ar com a distância com a fonte de radiação ionizante ${ }^{137} \mathrm{Cs}$ com dois filtros atenuadores ao detector.

Figura 21. Variação da taxa de kerma no ar com a distância com a fonte de radiação ionizante ${ }^{137} \mathrm{Cs}$ com três filtros atenuadores ao detector.

Figura 22. Variação da taxa de kerma no ar com a distância com a fonte de radiação ionizante ${ }^{60} \mathrm{Co}$ sem filtro atenuador ao detector.

Figura 23. Variação da taxa de kerma no ar com a distância com a fonte de radiação ionizante ${ }^{60} \mathrm{Co}$ com um filtro atenuador ao detector.

Figura 24. Variação da taxa de kerma no ar com a distância com a fonte de radiação ionizante ${ }^{60} \mathrm{Co}$ com dois filtros atenuadores ao detector.

Figura 25. Variação da taxa de kerma no ar com a distância com a fonte de radiação ionizante ${ }^{60} \mathrm{Co}$ com três filtros atenuadores ao detector. 46

Figura 26. Homogeneidade do campo de radiação a um metro do OB85/1

Figura 27. Homogeneidade do campo de radiação a quatro metros do OB85/1

Figura 28. Variação da taxa de kerma no ar com a distância com a fonte de ${ }^{137} \mathrm{Cs}$ realizada sem filtro atenuador ao detector.

Figura 29. Variação da taxa de kerma no ar com a distância com de ${ }^{137} \mathrm{Cs}$ realizada com um filtro atenuado ao detector.

Figura 30. Homogeneidade do campo de radiação a um metro do CaesaGammatron.

Figura 31. Homogeneidade do campo de radiação a quatro metros do CaesaGammatron.

Figura 32. Arranjo experimental para realização do teste de dependência angular a $0^{\circ}, 45^{\circ}$ (esquerda e direita) e $90^{\circ}$ .54

Figura 33. Arranjo experimental para verificação da atividade da fonte de ${ }^{137} \mathrm{Cs}$ do irradiador Hopewell. 


\section{LISTA DE TABELAS}

Tabela 1. Medidas de taxa de kerma no ar com diferentes detectores de modelo teletector com diferentes tensões aplicadas (baterias com tensão usual e com tensão

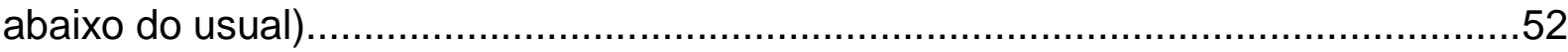

Tabela 2. Medidas de dependência angular dos Teletectors..................................54

Tabela 3. Medidas de taxa de kerma no ar com diferentes detectores do modelo

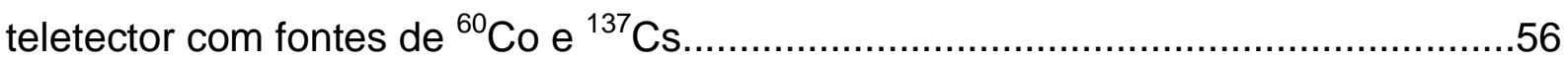

Tabela 4. Ensaios de estouro de escala de monitores portáteis do tipo Geiger- Müller

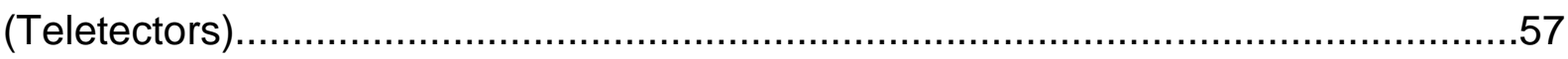




\section{INTRODUÇÃO}

O Laboratório de Calibração de Instrumentos do Instituto de Pesquisas Energéticas e Nucleares (LCI - IPEN) realiza, há mais de 30 anos (POTIENS, 2011; SILVA, 2012), calibração de instrumentos de medidas de radiação (RT-LCI001, 2011), os quais são empregados em rotinas de radioproteção, radiodiagnóstico e radioterapia. Este serviço é prestado a hospitais, indústrias, clínicas, universidades e outros usuários localizados em todo o Brasil. O LCl pertence à Gerência de Metrologia das Radiações (GMR), do Instituto de Pesquisas Energéticas e Nucleares que é uma autarquia estadual associada à Universidade de São Paulo (USP) e gerida técnica e administrativamente pela Comissão Nacional de Energia Nuclear (CNEN).

O LCI-IPEN realiza anualmente cerca de 800 calibrações (procedimentos realizados com a finalidade de verificar as condições operacionais dos instrumentos) e ainda irradiação de dosímetros, que são utilizados em radioproteção, radioterapia, radiodiagnóstico e medicina nuclear (POTIENS, 2011; RT-LCl-001, 2011).

Os medidores utilizados em radioproteção representam a grande maioria dos testes realizados, cerca de $60 \%$ dos instrumentos rotineiramente testados bem como as amostras irradiadas são utilizados em medidas de radioproteção (com radiação gama de ${ }^{137} \mathrm{Cs}$ ).

Para este tipo de medida o LCI-IPEN dispõe de um Sistema Irradiador, modelo OB 85/1, com fontes de ${ }^{137} \mathrm{Cs}$ e ${ }^{60} \mathrm{Co}$. Este sistema tem possibilitado a realização de testes na maioria dos instrumentos enviados ao LCI-IPEN, mas devido às novas tecnologias empregadas nesses instrumentos e ao decaimento radioativo das fontes de radiação, alguns detectores com valores de escala superiores a $10,0 \mathrm{R} / \mathrm{h}\left(25,8 \times 10^{-4} \mathrm{C} / \mathrm{kg}\right)$ não podem ser devidamente testados 
(POTIENS, 2011).

A melhora na qualidade dos seus processos de calibração e testes tem sido uma preocupação constante nos projetos de pesquisa e desenvolvimento no LCI-IPEN (RT-LCI-001, 2011), incluindo a diminuição de incertezas e identificação dos principais fatores que contribuem para estas incertezas (SRS 16, 2000; RTLCl-001, 2011). Além disso, é um dos poucos laboratórios autorizados pelo Laboratório Nacional de Metrologia das Radiações lonizantes (LNMRI) e que possui arranjos para calibração e testes nos quatro níveis de aplicação de monitores de radiação (Radioproteção, Radioterapia, Radiodiagnóstico e Medicina Nuclear), com fontes e sistemas de radiações alfa, beta, gama e X, e que atende a clientes de todo o Brasil, principalmente os da região sudeste, além de clientes de países vizinhos ( VIVOLO, 2000; TASIC, 2002; SANTOS, 2005; POTIENS 2011).

Anualmente o LCI-IPEN deixa de calibrar e/ou testar cerca de 150 instrumentos portáteis medidores de radiação no seu intervalo total de medição, por exemplo, o detector teletector realiza medições de taxas de exposição de aproximadamente $1000 \mathrm{R} / \mathrm{h}\left(10 \mathrm{~Sv} \cdot \mathrm{h}^{-1}\right)$. Porém o sistema atual de calibração de monitores portáteis do LCl fica impossibilitado de realizar a calibração em toda faixa de escala do equipamento, incluindo o teste de estouro de escala.

O sistema de calibração de monitores portáteis utilizado atualmente é o sistema irradiador OB85/1, assim como descrito acima e o laboratório também possui o sistema irradiador Caesa-Gammatron com fonte de ${ }^{137} \mathrm{Cs}$ com intervalo de taxa de kerma no ar de $(7,09 \pm 0,01) \mathrm{mGy} \cdot \mathrm{h}^{-1}$ a $(1318,26 \pm 0,15) \mathrm{mGy} \cdot \mathrm{h}^{-1}$ (SILVA, 2012), porém este sistema não está sendo ainda utilizado para realização do procedimento de calibração de monitores portáteis de radiação.

O LCl adquiriu um novo sistema irradiador gama da Hopewell Designs modelo G10-2-360-E com fonte de ${ }^{137} \mathrm{Cs}$ com atividade de 3,64 TBq, o qual nos permite obter uma taxa de kerma no ar de aproximadamente $(0,559 \pm 0,08)$ Gy. $h^{-1}$ (a distância de referência para determinação da taxa de kerma no ar é de $1 \mathrm{~m}$ (SRS 16, 2000; RT-LCl-001, 2011). Portanto, uma vez implementados estes novos sistemas irradiadores será possível realizar a calibração de praticamente todas as escalas de medida dos monitores de radiação. 
Estes instrumentos portáteis medidores de radiação que possuem escalas de leitura para alta taxa de radiação são instrumentos previstos para serem utilizados em situações de emergência. Também a norma CNEN-NN-3.01 Diretrizes Básicas de Proteção Radiológica (CNEN-NN-3.01, 2005), estabelece que os serviços de proteção radiológica devam assegurar que a calibração de equipamentos usados para dosimetria de feixes e fontes seja rastreada por um laboratório padrão de dosimetria, reconhecido ou autorizado pela CNEN; além disso, todas as normas da CNEN que estabelecem requisitos de radioproteção e segurança nas instalações nucleares e radioativas e outros serviços na área médica e industrial que utilizam material radioativo estabelece a utilização de instrumentos adequados e devidamente calibrados na sua faixa de utilização (CNEN-NN-6.05,1985; CNEN-NN-5.01, 1988; CNEN-NN-6.01, 1998; CNEN-NN$3.02,1998)$.

Logo um plano de proteção radiológica deve prever, em caso de emergência, a monitoração do local com um instrumento adequado para estas medições (CNEN-NN-3.01, 2005). A utilização de um instrumento descalibrado numa situação de emergência pode indicar um falso resultado, implicando numa exposição maior ao trabalhador. Se nesta situação de emergência for uma situação de alta taxa de kerma no ar (maior grau de periculosidade) é extremamente necessária à quantificação da intensidade dessa taxa, o elemento radioativo, o tempo de permanência da individuo no local, a distância entre o elemento radioativo e o indivíduo, dentre outros parâmetros. Assim, é possível determinar a dose equivalente no tecido ou no individuo como um todo, sendo possível ainda analisar a partir da dose efetiva os efeitos causados pela radiação ionizante (CNEN-NN-5.01, 1988; CNEN-NN-3.02, 1998;). 


\section{OBJETIVOS}

O objetivo deste trabalho foi desenvolver uma metodologia de avaliação para monitores portáteis de radiação em altas taxas de exposição e aprimorá-la para garantir a calibração destes em todas as escalas e com confiabilidade de medição.

Os objetivos específicos deste trabalho foram:

- Realizar o teste de fuga de corrente (controle de qualidade) no equipamento de referência de radioproteção composto por eletrômetro + cabo + câmara de ionização de volume sensível $1000 \mathrm{~cm}^{3}$ e também nas câmaras de $30 \mathrm{~cm}^{3}$ e $0,30 \mathrm{~cm}^{3}$ para realização dos outros testes.

- Caracterizar o sistema irradiador com fontes de ${ }^{60} \mathrm{Co},{ }^{137} \mathrm{Cs}$, com diferentes taxas de kerma no ar; marca STS, modelo: OB 85/1. Determinar a grandeza de referência e a variação da taxa de kerma no ar com a distância do campo de radiação no intervalo de calibração e ainda realizar um estudo e avaliação da homogeneidade do campo de radiação no intervalo de calibração; para o ${ }^{60} \mathrm{Co},{ }^{137} \mathrm{Cs}$;

- Caracterizar o sistema irradiador Caesa-Gammatron (irradiador de teleterapia) com uma única fonte de ${ }^{137} \mathrm{Cs}$. Determinar a grandeza de referência, realizar a variação da taxa de kerma no ar com a distância do campo de radiação no intervalo de calibração com estudo e avaliação da homogeneidade do campo no intervalo de calibração;

- Caracterizar o novo sistema irradiador gama, com fonte de ${ }^{137} \mathrm{Cs}$, com blindagem, colimador e painel de controle eletrônico inclusos, marca Hopewell, modelo G10-2-360-E.

- Realizar testes de desempenho nos detectores de tipo Teletector, os quais são monitores portáteis de radiação gama que são muito utilizados nos 
serviços e nas rotinas operacionais de radioproteção em altas taxas de kerma no ar;

- Realizar um código de conduta para utilização do equipamento Teletector.

\subsection{Relevância e originalidade}

Caracterizado este novo sistema de irradiador gama (Hopewell) foi possível realizar o teste de estouro de escala, permitindo assim uma maior confiabilidade na calibração e consequentemente uma maior confiabilidade de medição pelo usuário do equipamento. Atualmente nenhum Laboratório de Calibração de Instrumentos no Brasil tem condições de aplicar o teste de estouro de escala (overload) (ABNT NBR 10011, 1987; SRS 16, 2000), pois ele prevê a irradiação do instrumento com uma taxa de exposição de cerca de dez vezes o valor do fundo de escala; o que torna este teste de difícil aplicação, pois ele possui condições técnicas muito específicas e difíceis de realização (POTIENS, 2011). 


\section{FUNDAMENTOS TEÓRICOS}

\subsection{Proteção Radiológica}

O principal objetivo da Proteção Radiológica é proporcionar um padrão de proteção ao ser humano sem limitar os benefícios da utilização das radiações ionizantes. A International Radiation Protection Commission (ICRP) estabelece recomendações em proteção radiológica que servem como base para programas e regulamentações mais completas emitidas por outras organizações internacionais e nacionais (ICRP, 1991). A ICRP publicou seu primeiro relatório em 1928. Este primeiro relatório, denominado Publicação 1, continha recomendações que foram adotadas em setembro de 1958. Recomendações subsequentes foram publicadas em 1964, em 1966 e em 1977.

A Publicação 26, de 1977, ampliada em 1978, foi atualizada nos anos de 1980 e 1987. As recomendações foram completamente revisadas e publicadas em 1991 como Publicação 60 (ICRP Publication 60); e no ano de 2007, estas recomendações foram formalmente substituídas pela publicação 103 (ICRP, 2007), que atualiza, consolida e fornece orientações adicionais sobre o controle de exposição a fontes de radiação publicadas desde 1990. Esta publicação também atualiza os fatores de ponderação no tecido utilizados nos cálculos das grandezas operacionais, dose equivalente e efetiva baseado nas últimas informações de biologia e física das radiações e mantêm os três princípios básicos da radioproteção: justificação, otimização e limitação de dose.

No Brasil, a Autoridade Regulatória na área nuclear é a Comissão Nacional de Energia Nuclear (CNEN), referência na área de radioproteção e responsável pela publicação das normas que regulamentam a utilização da radiação ionizante no Brasil. 


\subsection{Grandezas Dosimétricas}

\subsubsection{Atividade}

A atividade (A) é definida como sendo o número de transformações nucleares que ocorrem em uma dada amostra, por unidade de tempo (OKUNO\&YOSHIMURA, 2010). É dada pela equação (1):

$$
A=k \times N
$$

Onde:

(k) é a constante de desintegração

(N) é o número de átomos radioativos contidos na amostra ou material.

A unidade da atividade no Sistema Internacional é o Becquerel $(\mathrm{Bq})$, que equivale a uma desintegração radioativa por segundo. A unidade antiga é o Curie (Ci), sendo $1 \mathrm{Ci}=37 \mathrm{GBq}$ (KNOLL, 2000).

\subsubsection{Exposição}

Exposição $(\mathrm{X})$ é o quociente de $d \mathrm{Q}$ por $d \mathrm{~m}$, no qual $d \mathrm{Q}$ é a soma das cargas elétricas de todos os íons de um mesmo sinal, produzidos no ar quando todos os elétrons e pósitrons liberados pelos fótons, em um elemento de ar de massa $d \mathrm{~m}$, são completamente freados (SCAFF, 2004), conforme a equação (2):

$$
X=\frac{d Q}{d m}
$$

A unidade especial dessa grandeza é o Roentgen (R). No sistema internacional de unidades (SI), a unidade utilizada para exposição é Coulomb/kilograma (C/kg). A relação entre $R$ e $C / \mathrm{kg}$ é $1 \mathrm{R}=2,58 \times 10^{-4} \mathrm{C} / \mathrm{kg}$ (KNOLL, 2000; SCAFF, 2004).

\subsubsection{Dose Absorvida}

A dose absorvida (D) é a razão entre Energia Média (de) cedida pela radiação ionizante e a massa $(\mathrm{dm})$, onde a energia é depositada. Essa grandeza pode ser utilizada para qualquer tipo de radiação e medida em todo tipo de material (KNOLL, 2000), conforme a equação (3): 


$$
X=\frac{d \varepsilon}{d m}
$$

A unidade da dose absorvida no Sistema Internacional é $\mathrm{J} / \mathrm{kg}$, sendo a unidade de uso o Gray (Gy), onde 1 Gy equivale a $1 \mathrm{~J} / \mathrm{kg}$ (KNOLL, 2000; SCAFF, 2004).

\subsection{4 kerma}

A grandeza kerma (k) é definida como sendo a soma das energias cinéticas iniciais $(\mathrm{dE})$ de todas as partículas carregadas liberadas por partículas indiretamente ionizante incidentes em um material de massa (dm) (KNOLL, 2000; SCAFF, 2004). Esta grandeza é válida somente para a radiação indiretamente ionizante (gama, raios X e nêutrons), conforme a equação (4):

$$
K=\frac{d E}{d m}
$$

A unidade da grandeza Kerma é a mesma da grandeza dose absorvida, logo temos, J/kg ou Gy, sendo 1 Gy = 1 J/kg (KNOLL, 2000; SCAFF, 2004).

\subsection{Interação da radiação com a matéria}

\subsubsection{Radiação ionizante}

Qualquer forma de radiação que tenha energia suficiente para causar a liberação de um ou mais elétrons de um átomo é denominada radiação ionizante.

As formas comuns de uso na medicina são os raios $X$, gama e os elétrons, que também são utilizados na área industrial (gamagrafia, entre outros) e nos laboratórios de calibração de equipamentos (BITELLI, 1982).

Todas as radiações possuem energia, como no caso das partículas em movimento, ou por sua própria natureza, como é o caso das radiações eletromagnéticas. Ao atravessar um meio interagindo com a matéria, a radiação transfere sua energia (total ou parcialmente) para os átomos e moléculas deste meio. A transferência da energia de uma partícula ou de um fóton para os átomos do material absorvente (meio) ocorre por mecanismos de ionização e excitação (KNOLL, 2000; SCAFF, 2004). 
Um processo de interação no qual resulte a remoção de um elétron, de um átomo ou molécula, deixando-o com uma carga resultante positiva é denominado ionização. No entanto, a adição de energia a um sistema atômico ou molecular irá elevá-lo do estado normal de energia ao estado de excitação (BITELLI, 1982).

De um modo geral, quando partículas carregadas ou radiação eletromagnética atravessam a matéria, o mecanismo predominante da perda de energia é devido à interação delas com os elétrons do meio (material). No caso das partículas carregadas leves, isto é facilmente evidenciado a partir da dispersão que elas apresentam ao interagir com a matéria. Já as partículas pesadas (prótons, partículas alfa, entre outros) são pouco desviadas de sua direção original quando interagem, perdendo energia. Os elétrons, por sua vez, são desviados em ângulos muito maiores. As perdas de energia resultantes de colisões com núcleos são várias ordens de grandeza menores do que aquelas que ocorrem na interação com os elétrons. Isto não ocorre com os nêutrons, pois eles interagem quase que exclusivamente com os núcleos dos átomos (OKUNO\&YOSHIMURA, 2010).

\subsubsection{Interação de fótons com a matéria}

Entre os mecanismos principais de interação de fótons (raios gama ou $\mathrm{X}$ ) com a matéria pode-se citar três: o efeito fotoelétrico, o efeito Compton e a produção de pares. A probabilidade de ocorrência de cada um destes processos é determinada pela energia do fóton incidente e pelo número atômico do meio (material). $\mathrm{Na}$ interação entre um fóton e a matéria são emitidos ou criados elétrons ou pósitrons que ionizam os átomos do meio (KNOLL, 2000; SCAFF, 2004).

O efeito fotoelétrico é uma interação entre um fóton e um átomo. O fóton é absorvido pelo átomo e o elétron é ejetado. A energia cinética do elétron ejetado é igual à energia do fóton menos a energia de ligação do elétron no átomo. $A$ energia de ligação de um elétron é a energia que deve ser fornecida a ele para removê-lo do átomo (KNOLL, 2000; SCAFF, 2004).

O efeito Compton consiste na colisão entre um fóton e um elétron (que pode ser considerado livre) das camadas mais externas do átomo (SRS 16, 2000). 
Um elétron deste tipo pode ser considerado livre quando a energia do fóton incidente é muito maior que a energia de ligação do elétron. A energia cinética do elétron espalhado depende do ângulo de espalhamento. Nesse processo o fóton não é absorvido e, portanto, continua interagindo com os outros elétrons com energia menor que a inicial (KNOLL, 2000; SCAFF, 2004).

O processo de produção de pares elétron-pósitron ocorre quando a energia do fóton incidente é maior que pelo menos duas vezes a massa de repouso do elétron, isto é, 1,022 MeV. Neste processo, um fóton perde toda a sua energia em uma interação com o núcleo, criando um par elétron-pósitron, com certa energia cinética. O pósitron ao se aniquilar emite dois fótons de $511 \mathrm{keV}$ cada (KNOLL, 2000; SCAFF, 2004).

\subsubsection{Detectores de radiação}

Um detector de radiação consiste de um dispositivo que, quando colocado em um meio onde exista um campo de radiação, seja capaz de indicar a sua presença. A interação do meio detector com a radiação pode ocorrer por diversos processos pelos quais as radiações diferentes podem interagir com o material utilizado para se medir ou se indicar as características dessas radiações (KNOLL, 2000; DAMATTO, 2009).

Normalmente, um detector de radiação é constituído de um elemento ou material sensível à radiação e de um sistema que transforma esses efeitos em um valor relacionado a uma grandeza de medição dessa radiação. Os detectores a gás são conhecidos também como detectores por ionização em gases. Isto porque a radiação incidente no volume sensível (o gás) cria pares de íons que podem ser medidos em um dispositivo de medida elétrica (eletrômetro). $O$ detector de tipo teletector é a gás do tipo Geiger-Muller (KNOLL, 2000; SCAFF, 2004).

\subsubsection{Detectores de Geiger-Muller}

O detector Geiger-Muller consiste em um cilindro de metal fechado em ambas às extremidades, uma das quais é fechada com uma película fina (geralmente mica), que constitui a janela do detector. No eixo do cilindro é 
colocado um fio metálico rígido e o interior do tubo é preenchido com uma mistura de um gás inerte a baixa pressão (em geral argônio) e um gás de congelamento, que pode ser vapor de um composto orgânico ou de halogênio, cuja função é inibir a ionização desenfreada do gás. Entre o fio central (ânodo) e o corpo cilíndrico (cátodo) é aplicada uma grande diferença de potencial (KNOLL, 2000; SCAFF, 2004).

Quando uma radiação entra no detector o gás é ionizado provocando a formação de íons e elétrons livres. O forte campo elétrico criado entre os eletrodos do tubo acelera os íons positivos em direção ao cátodo e os elétrons em direção ao ânodo. Perto do ânodo, na região de avalanche, os elétrons ganham energia suficiente para ionizar moléculas adicionais de gás e criar um grande número de avalanches de elétrons, que se espalham ao longo do ânodo e de forma eficaz em toda a região da avalanche (KNOLL, 2000; SCAFF, 2004).

Este é o efeito de multiplicação de gás, que dá ao tubo a sua principal característica de ser capaz de produzir um impulso de saída significativo de um único evento ionizante, gerando assim um pulso elétrico que é registrado no circuito contador (KNOLL, 2000; SCAFF, 2004).

\subsubsection{Calibração de instrumentos}

Segundo o VIM - Vocabulário Internacional de Metrologia, Conceitos Fundamentais e Gerais e Termos Associados (2012), calibração de instrumentos pode ser definida como:

Operação que estabelece, sob condições especificadas, numa primeira etapa, uma relação entre os valores e as incertezas de medição fornecidos por padrões e as indicações correspondentes com as incertezas associadas; numa segunda etapa, utiliza esta informação para estabelecer uma relação visando a obtenção de um resultado de medição a partir de uma indicação.

Esta avaliação é feita por meio de testes seguindo as recomendações do laboratório de referência designado pelo INMETRO, o Laboratório Nacional de Metrologia das Radiações Ionizantes (LNMRI), do Instituto Radioproteção Dosimetria (IRD) - RJ; o LCI do IPEN segue as recomendações do LNMRI (RT- 
LCI-001, 2011; POTIENS, 2011).

Por meio da calibração obtém-se um fator multiplicativo, que converte um valor indicado (corrigido para as condições denominadas de referência) para o que se denomina de "valor convencional" de uma grandeza medida, sendo chamado "fator de calibração" (IAEA 1595, 2008, DAMATTO and VIVOLO, 2009; DAMATTO, 2011).

Os instrumentos monitores de radiação gama podem ser calibrados no LClIPEN pelo método de campos bem conhecidos e método de substituição (ISO 4037-1, 1996; KNOLL, 2000; DAMATTO and VIVOLO, 2011, DAMATTO, 2011), sendo utilizado o método de campos bem conhecido pelo laboratório gama, ou seja, todas as características do feixe de radiação são determinadas periodicamente utilizando-se o sistema de referência, sendo assim determinada a grandeza de referência kerma no ar (KNOLL, 2000).

O documento SRS 16 da AIEA, estabelece as principais diretrizes na implantação de métodos e procedimentos de calibração de monitores de radiação a serem utilizados nos laboratórios de calibração de instrumentos dentro de uma cadeia metrológica (IEC 395, 1972; IAEA, 1585, 2008). No Brasil, o documento que regulamenta o funcionamento de um laboratório para a atividade de calibração de monitores utilizados em radioproteção foi formalmente publicado no ano de 2011 pelo Comitê de Avaliação de Serviços de Ensaio e Calibração CASEC do IRD (RT-LCI-001, 2011).

De acordo com os critérios do CASEC, as calibrações devem ser sempre realizadas com fonte de ${ }^{137} \mathrm{Cs}$, exceto nos casos em que o fabricante recomenda outra energia para calibração. A fonte de ${ }^{60} \mathrm{Co}$ deverá ser utilizada para o teste de dependência energética em um dos pontos ajustáveis (RT-LCl-001, 2011; POTIENS, 2011).

\subsubsection{Revisão Bibliográfica}

A norma CNEN-NN-3.01 "Diretrizes Básicas de Proteção Radiológica", revisada em janeiro de 2005 (CNEN-NN-3.01, 2005), estabelece que os serviços de proteção radiológica devam assegurar que a calibração de equipamentos usados para calibrar feixes e fontes seja rastreada por um laboratório padrão de 
dosimetria, reconhecido ou autorizado pela CNEN; além disso, todas as normas da CNEN que estabelecem requisitos de radioproteção e segurança nas instalações nucleares e radioativas e outros serviços na área médica e industrial que utilizam material radioativo preveem a utilização de instrumentos adequados e calibrados na sua faixa de utilização (CNEN-NN-3.02, 1998; CNEN-NN-5.01, 1988; CNEN-NN-6.05,1985; CNEN-NN-6.01, 1998).

Um plano de proteção radiológica deve prever, em uma situação de emergência a monitoração do local com um instrumento adequado para estas medidas. A utilização de um instrumento descalibrado em uma situação de emergência pode indicar um falso resultado, implicando numa exposição maior ao trabalhador.

Um instrumento que passa por um teste de estouro de escala deve ser capaz de manter a sua indicação por, pelo menos 5 minutos quando exposto a uma taxa maior do que 10 vezes o seu fundo de escala (IEC 395, 1972; ICRP, 2007). No Brasil, há uma estimativa de que mais de 150 modelos de instrumentos apresentam escalas de medida de taxa de exposição maiores do que o limite de taxa de exposição que os laboratórios de calibração, atualmente autorizados, possam calibrar. Assim, o que impossibilita a calibração destes equipamentos e ainda não permite a realização dos testes de estouro de escala neles é a alta taxa de exposição necessária para se atingir 10 vezes maior que o seu fundo de escala. 


\section{MATERIAIS E MÉTODOS}

\subsection{Materiais}

\subsubsection{Sistemas de Irradiação}

Foram utilizados três irradiadores neste trabalho:

- Sistema irradiador com controle remoto de acionamento e controle de tempo de irradiação com fontes de ${ }^{60} \mathrm{Co}$ e ${ }^{137} \mathrm{Cs}$, com diferentes taxas de kerma no ar; marca tipo STS, modelo: OB 85/1, FIG. 1.

Atividade da fonte de ${ }^{60} \mathrm{Co}: 37 \mathrm{GBq}( \pm 10 \%)$ em 11 de maio de 1995 e da fonte de ${ }^{137}$ Cs: $740 \mathrm{GBq}(+15 \%-10 \%)$ em 28 de abril de 1995.

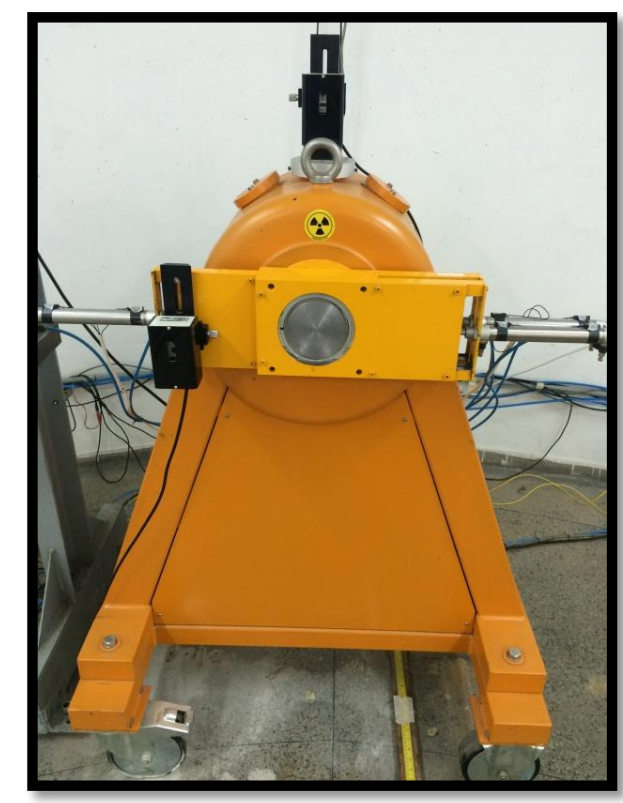

FIGURA 1. Sistema irradiador marca STS, modelo OB $85 / 1$, com fontes de ${ }^{60} \mathrm{Co},{ }^{137} \mathrm{Cs}$

- Sistema irradiador Caesa-Gammatron (irradiador de teleterapia) com acionador elétrico por meio de um painel de comando confeccionado pelo LCI-IPEN e que possui um controle de tempo de irradiação com uma única fonte de ${ }^{137} \mathrm{Cs}$, FIG. 2. 
Atividade da fonte de ${ }^{137} \mathrm{Cs}: 17.862,3 \pm 4,4 \mathrm{GBq}$ em 19 de junho de 2010 (SILVA, 2012).

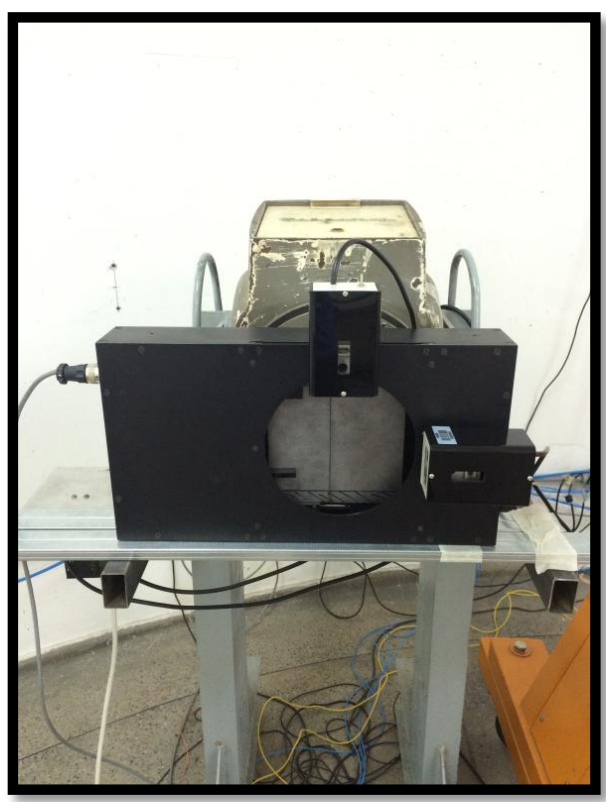

FIGURA 2. Sistema irradiador Caesa-Gammatron com fonte de ${ }^{137} \mathrm{Cs}$

- Sistema irradiador gama com blindagem, colimador e painel de controle eletrônico inclusos, marca Hopewell, modelo G10-2-360-E, e uma fonte de ${ }^{137} \mathrm{Cs}$, FIG. 3.

Atividade da fonte de ${ }^{137} \mathrm{Cs}:$ 3,64 TBq em 01 de março de 2014.

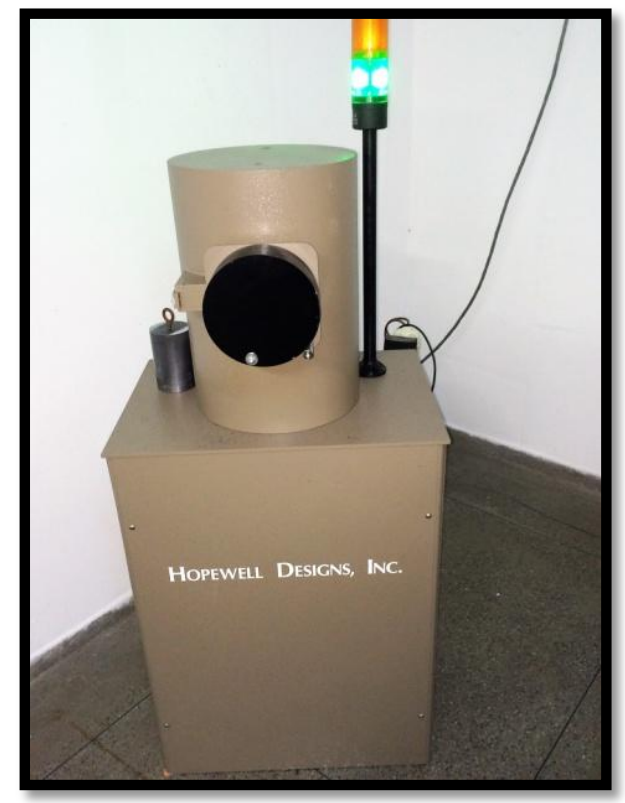

FIGURA 3. Sistema irradiador marca Hopewell, modelo G10-2-360-E, com fonte de ${ }^{137} \mathrm{Cs}$ 


\subsubsection{Sistema de Referência de Medida (Nível Radioproteção):}

Foram utilizadas câmaras de ionização com volume sensível de $1000 \mathrm{~cm}^{3}$ (modelo 32002), $30 \mathrm{~cm}^{3}$ (modelo 23361), 0,3 $\mathrm{cm}^{3}$ (modelo 31013), da marca PTW; eletrômetro marca PTW, modelo UNIDOS e cabo PTW triaxial para conexão entre as câmaras de ionização e o eletrômetro, apresentados nas FIG. 4, 5, 6 e 7, respectivamente.

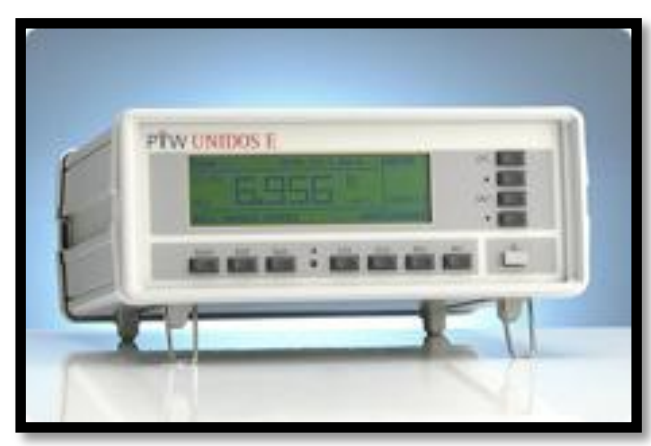

FIGURA 4. Eletrômetro marca PTW, modelo UNIDOS

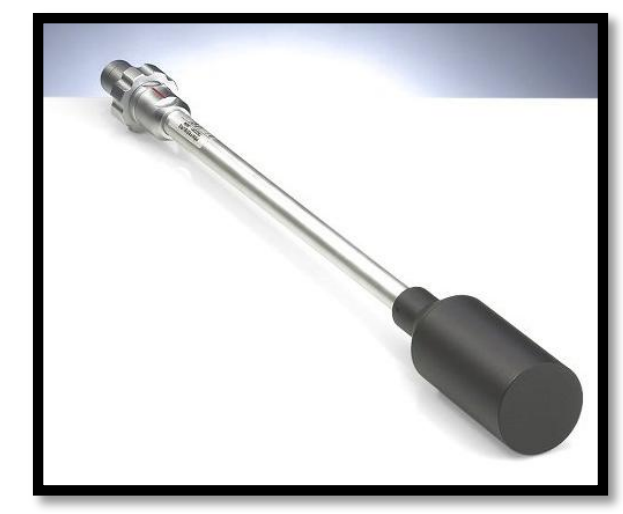

FIGURA 5. Câmara de ionização com volume sensível $30 \mathrm{~cm}^{3}$ (modelo 23361)

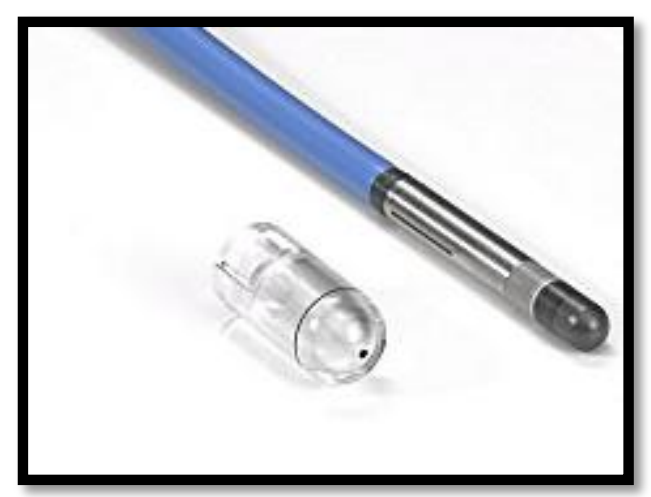

FIGURA 6. Câmara de ionização com volume sensível $0,30 \mathrm{~cm}^{3}$ (modelo 31013) 


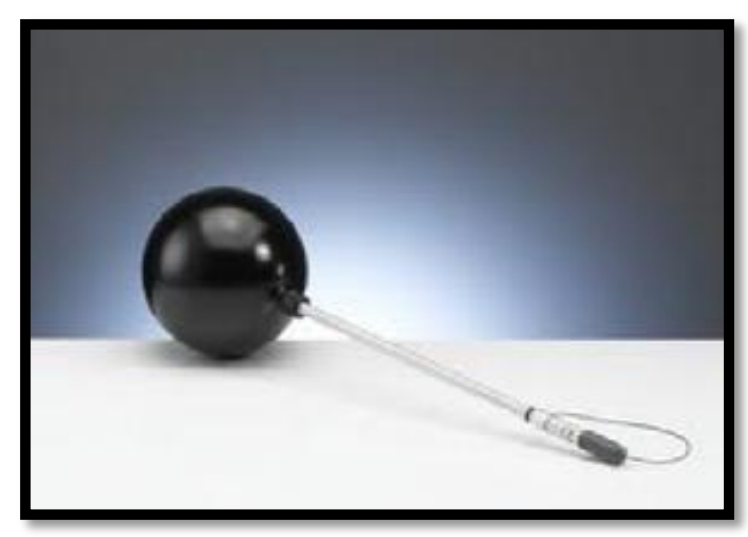

FIGURA 7. Câmara de ionização com volume sensível de $1000 \mathrm{~cm}^{3}$ (modelo 32002)

\subsubsection{Equipamentos testados}

Foram utilizados detectores do tipo teletector da marca Automess modelo 6112M digital e analógico modelo 6150 para a realização dos testes; este sistema de detecção possue dois detectores do tipo Geiger Müller de diferentes intervalos ou faixa de operação $(0.01 \mu \mathrm{Sv} / \mathrm{h}$ a $10 \mathrm{~Sv} / \mathrm{h})$ com seleção automática do detector G.M., ou seja, quando a taxa de exposição for maior que $10 \mathrm{mSv} / \mathrm{h}$ o detector muda para a alta gama e quando a taxa de exposição for menor que $7 \mathrm{mSv} / \mathrm{h}$ retorna à baixa gama. Este sistema de detecçào também possui unidades de exibição em Roentgen (R), Sievert (Sv) ou Gray (Gy). Por se tratar de um equipamento portátil o mesmo funciona com quatro baterias alcalinas do tipo $\mathrm{C}$ ou uma bateria alcalina de 9V. Também possui um telescópio de 4 metros permitindo assim medidas de longa distância entre operador e fonte.

Na FIG. 7 é apresentado um dos detectores de modelo teletector utilizados neste trabalho.

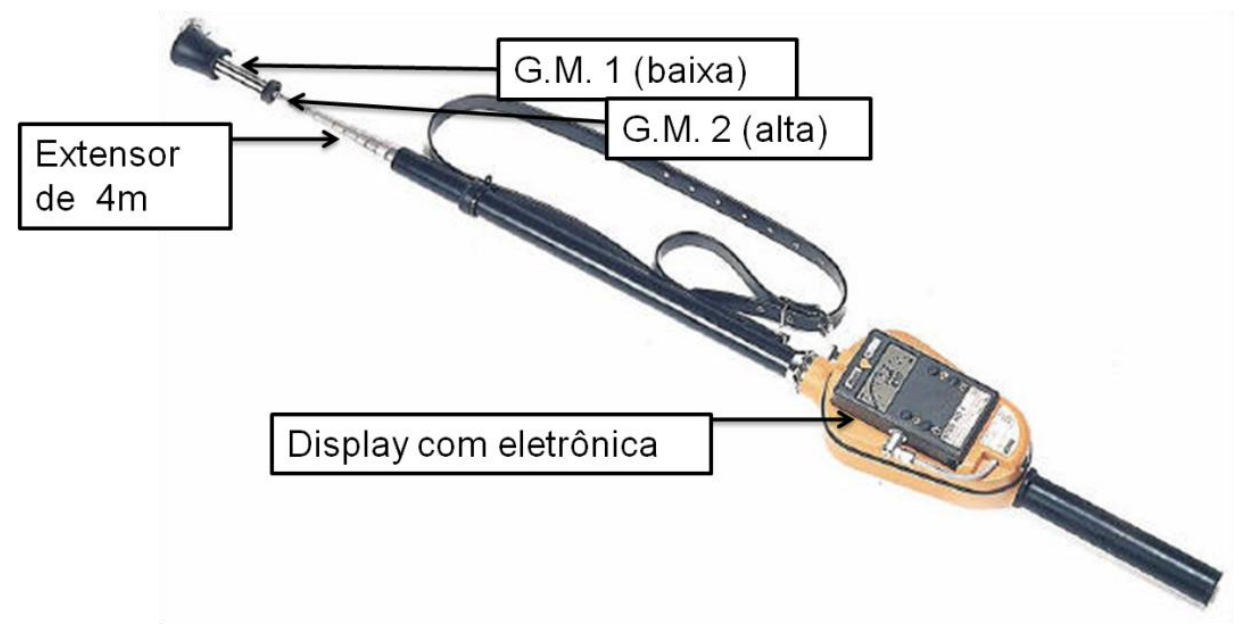

FIGURA 8. Detector de modelo teletector 


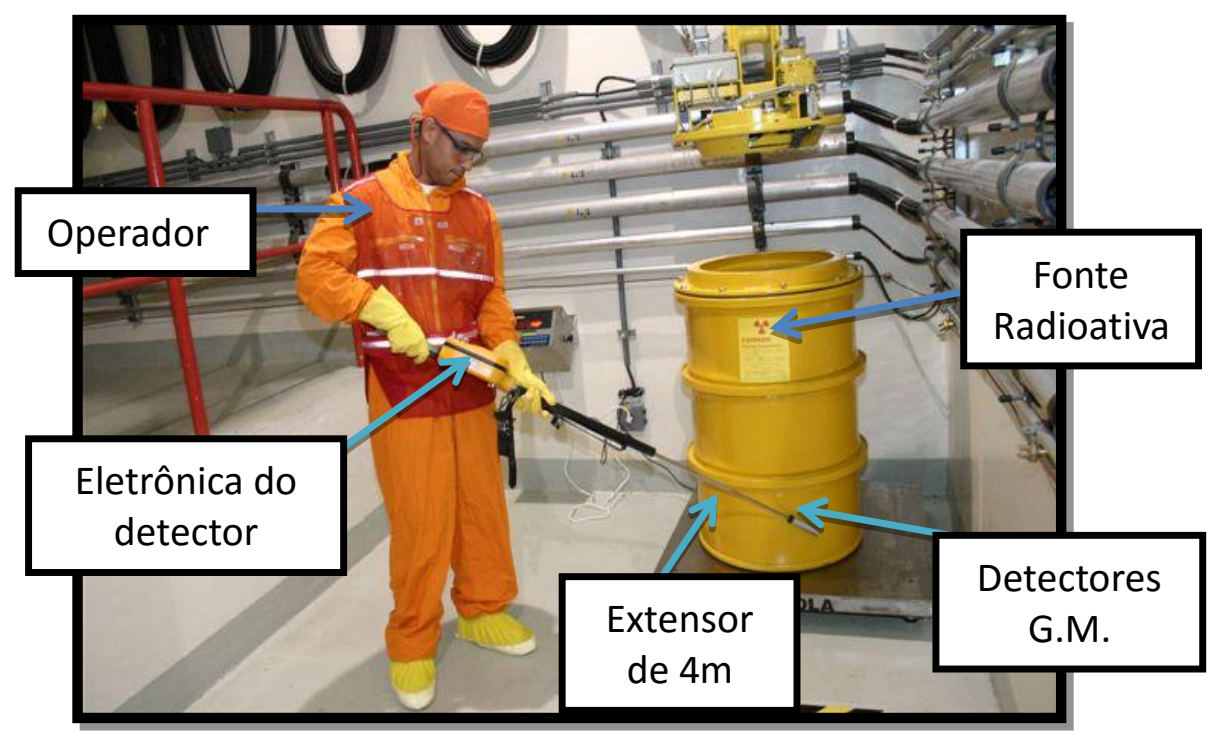

FIGURA 9. Exemplificação da utilização de um Teletector em rotina (http://abrahao-radiologia.blogspot.com.br/2010/10/rejeitos-radioativos.html)

\subsubsection{Sistemas Auxiliares e Acessórios Importantes}

Foram utilizados os seguintes equipamentos para realização dos testes neste trabalho: desumidificadores e climatizadores de ambiente, computador desktop, modelo PC, termômetro Incotherm, de mercúrio, com intervalo de medida entre $-10^{\circ} \mathrm{C} \mathrm{e}+40^{\circ} \mathrm{C}$ e precisão $\pm 5 \%$, barômetro Veränderlich, modelo Domatic, Alemanha, com intervalo de medida entre $96 \mathrm{kPa}$ e $104 \mathrm{kPa}$ e precisão de $0,1 \mathrm{kPa}$, higrômetro Präzision-Faden, Alemanha, com intervalo de medida entre $0 \%$ e $100 \%$ e com precisão de $1 \%$ de umidade relativa do ar, mesa automatizada para suporte e posicionamento dos equipamentos e lasers para posicionamento modelo Lumina-L2.

Nas FIG. 9 e 10 são apresentadas as salas de controle e de irradiação no Bunker do LCl, respectivamente, e nas FIG. 11 e 12 são apresentadas as salas de controle e de irradiação para o irradiador Hopewell, respectivamente. 


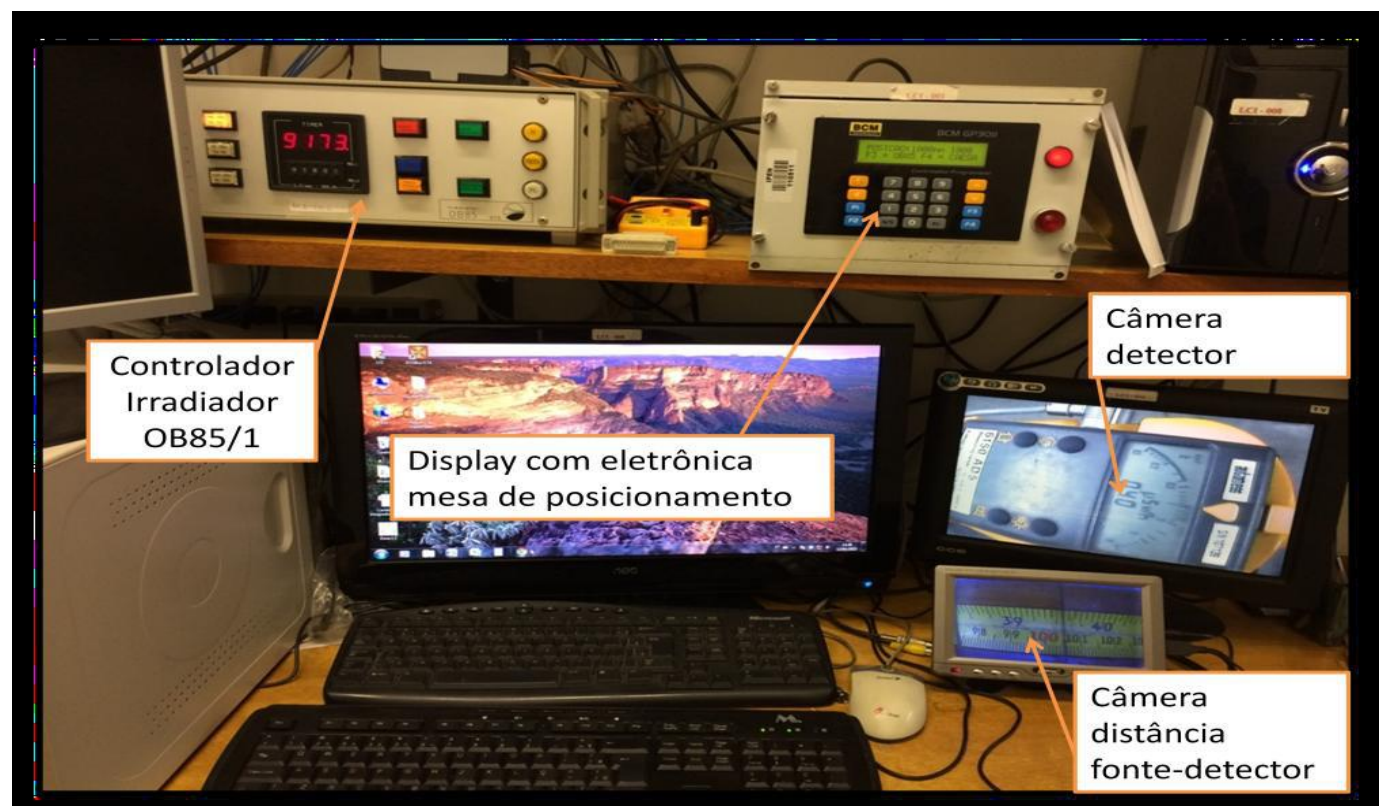

FIGURA 9. Sala de controle do laboratório de calibração de monitores portáteis.

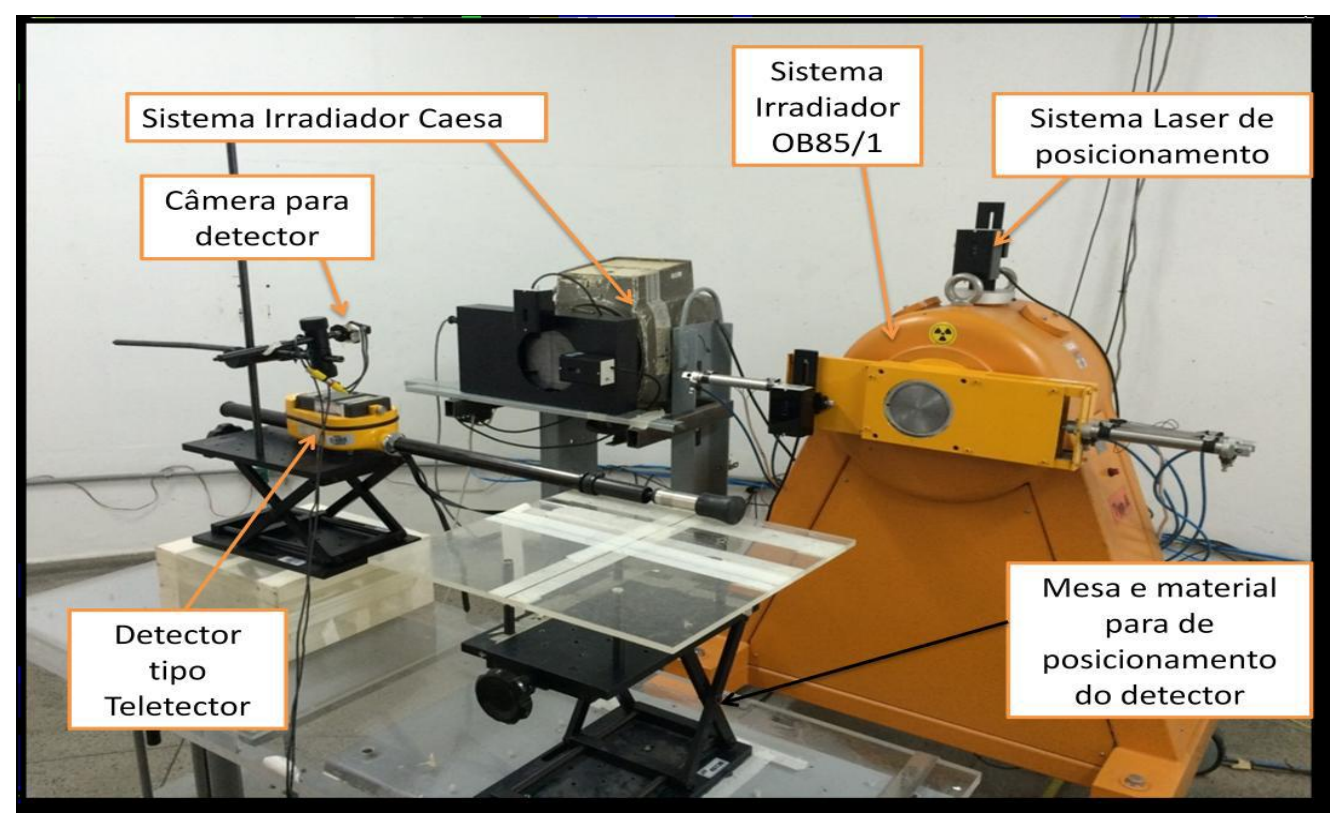

FIGURA 10. Sala de irradiação do laboratório de calibração de monitores portáteis (LCIIPEN). 


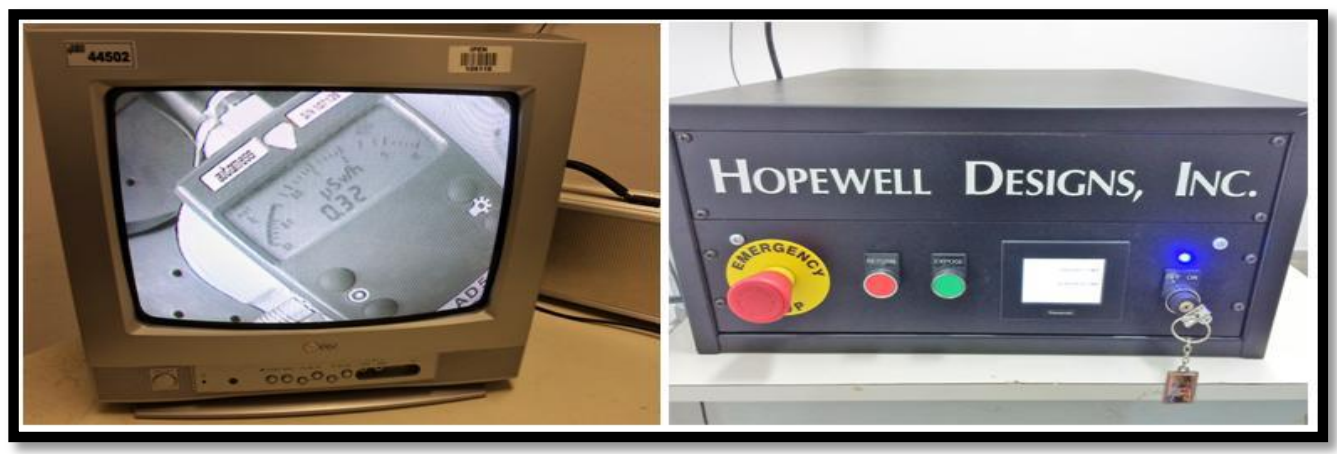

FIGURA 11. Sala de controle do laboratório do irradiador Hopewell.

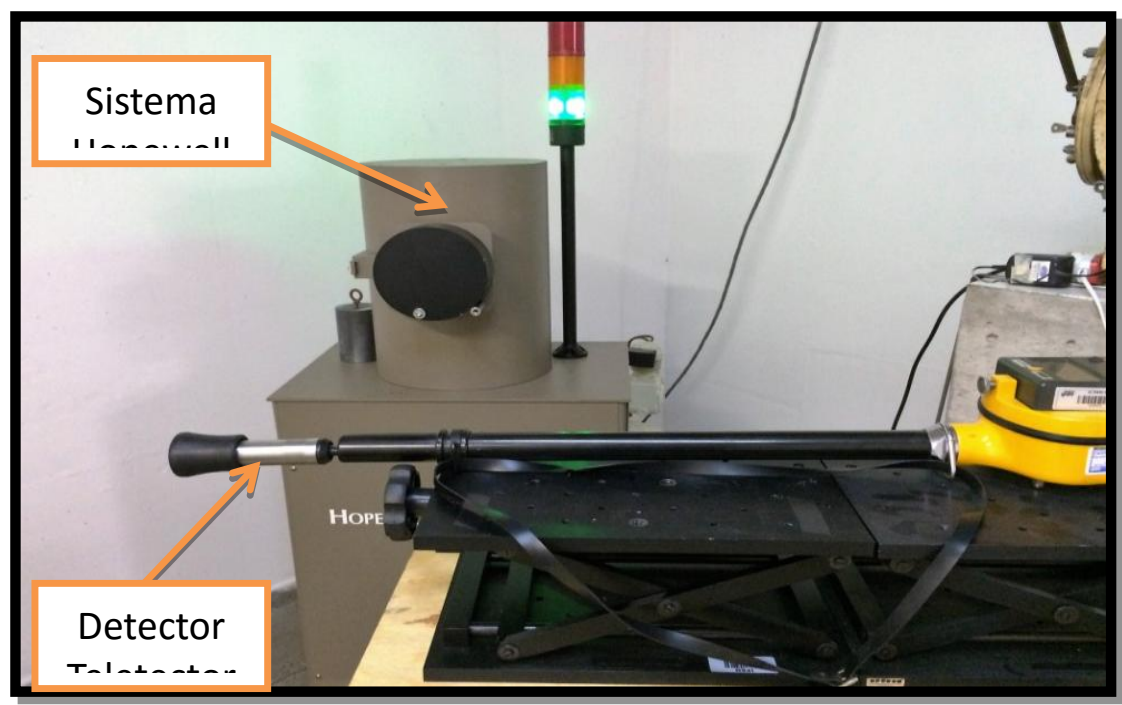

FIGURA 12. Sala de irradiação do irradiador Hopewell.

\subsection{Métodos}

Inicialmente foi realizado um levantamento bibliográfico e um estudo da literatura pertinente ao assunto abordado. Paralelamente, foi realizado um estudo dos sistemas de detecção de alta taxa de exposição e kerma no ar, com testes de desempenho e controle de qualidade nos sistemas de detecção de referência do LCI que foram utilizados na determinação na caracterização dos sistemas irradiadores.

Foi realizado também o teste de fuga de corrente na pré-irradiação, que consiste em medições sem a câmara estar na presença de radiação ionizante (IAEA 1582, 2008). Assim, o equipamento não deverá ler nenhum tipo de corrente ou carga, pois não ocorrerá ionização das moléculas de ar no detector e logo não 
poderá ter leitura. Se ocorrer medição é possível observar a variação percentual do conjunto, detector + cabo + eletrômetro.

Foram realizados testes específicos para cada componente, ou seja, foi utilizado um segundo conjunto clínico calibrado que não possuia fuga de corrente e foi revezado cada componente durante os testes de fuga e foram realizadas nas três câmaras de ionização, volumes $1000 \mathrm{~cm}^{3}, 30 \mathrm{~cm}^{3}$ e $0,3 \mathrm{~cm}^{3}$. Foram cumpridos os testes na câmara de $1000 \mathrm{~cm}^{3}$, pois esta possui calibração pelo IRD; na câmara de $30 \mathrm{~cm}^{3}$, caso a câmara de $1000 \mathrm{~cm}^{3}$ indicasse fuga de corrente utilizaríamos esta e a câmara de $0,3 \mathrm{~cm}^{3}$ para o teste de homogeneidade dos campos de radiações que serão caracterizados.

\subsubsection{Caracterização dos campos de radiação}

Para a determinação das principais características do campo de radiação, como taxa de kerma no ar, homogeneidade, espalhamento, entre outros, foi seguida a metodologia proposta pela norma ISO 4037-1 (ISSO 4037-1, 1996). Também foi realizada a dosimetria do feixe de radiação em todo o intervalo de distância do banco ótico, assim como as determinações de suas incertezas de acordo com as normas da Agência Internacional de Energia Atômica - AIEA ( ISO 4037-1, 1996; IEC 60731, 1997; SRS 16, 2000; ISSO/IEC 17025, 2006; IAEA 1585,2008 ) para os sistemas de irradiadores OB 85/1 e Caesa-Gammatron.

\subsubsection{Teste de desempenho}

A verificação das características operacionais dos monitores portáteis de radiação foi realizada por meio de testes de desempenho, os quais podem ser definidos como um conjunto de procedimentos (ensaios e testes) que permitem avaliar atualmente as condições operacionais dos equipamentos (; IEC 395, 1972; SRS 16, 2000; RT-LCI-001, 2011; IAEA 1585, 2008).

\subsubsection{Dependência energética}

A dependência energética de um monitor portátil de radiação pode ser definida como a variação na resposta do instrumento em função da energia da radiação, para um mesmo tipo de radiação e taxa de dose absorvida referenciada 
ao tecido ou no ar, em princípio, para todo o intervalo de energias em que o equipamento foi projetado para medir. Deve-se manter o valor da taxa de exposição constante (IEC 395, 1972; SRS 16, 2000; IAEA 1585, 2008; RT-LCI001, 2011).

\subsubsection{Dependência angular}

Se os instrumentos portáteis de medida de radiação são utilizados sob condições de falta de uniformidade de irradiação do volume sensível do seu elemento detector (próximo à fonte ou a um feixe de radiação), a resposta do equipamento poderá variar significativamente com a geometria da fonte, a geometria do detector, e ainda com a distância entre a fonte e o detector, chamando assim de dependência angular (; IEC 395, 1972; SRS 16, 2000; RTLCI-001, 2011; IAEA 1585, 2008).

\subsubsection{Teste de estouro de escala (overload)}

O teste de estouro de escala (overload) faz parte dos ensaios denominados de "Condições de Segurança". Para taxas de exposição correspondendo a indicações acima do limite superior de qualquer faixa nominal, o mostrador do instrumento deve acusar estouro de escala, ou seja, um instrumento que passa por um teste de estouro de escala deve ser capaz de manter a sua indicação por, pelo menos 5 minutos quando exposto a uma taxa maior do que 10 vezes o valor de seu fundo de escala (IEC 395, 1972; IAEA 1585, 2008;).

\subsubsection{Verificação do sistema irradiador Hopewell}

O sistema irradiador de marca Hopewell com fonte de radiação ionizante ${ }^{137} \mathrm{Cs}$ foi adquirido recentemente pelo LCI. Assim, para realização de uma verificação de sua atividade foram realizadas cinco medições e para determinação do valor médio da taxa de exposição com suas devidas incertezas e logo com este valor foram realizados os cálculos de atividade para comparação de atividade medida com a especificada em seu certificado. 


\subsubsection{Código de conduta para utilização do Teletector}

Após a análise dos testes de desempenho do detector de radiação ionizante de alta taxa de kerma no ar do tipo Teletector foi desenvolvido um código de conduta para o usuário deste, podendo assim utilizar o equipamento com maior confiabilidade possível.

Também após realizar a caracterização dos três irradiadores será analisada a metodologia de calibração dos instrumentos medidores de altas taxas pelo Gerente Técnico do laboratório seguindo as recomendações do SRS 16 (2000), da AIEA e do Laboratório Nacional de Metrologia das Radiações lonizantes com o resultados apresentados neste trabalho, atualizando-a. 


\section{RESULTADOS E DISCUSSÕES}

\subsection{Caracterização dos sistemas irradiadores}

Para realização da caracterização dos sistemas irradiadores foi utilizado o sistema de detecção de referência do $\mathrm{LCl}$ que é composto por câmaras de ionização, eletrômetro e cabo triaxial para conexão. Assim, primeiramente, foi realizado teste de controle de qualidade dos sistemas de detecção para posteriormente realizar a caracterização dos sistemas irradiadores.

\subsection{Testes de controle de qualidade do sistema de referência}

Foi realizado o teste de fuga de corrente do detector de referência do $\mathrm{LCl}$, que consiste de um eletrômetro modelo PTW, três câmaras de ionização com volume sensível de: $1000 \mathrm{~cm}^{3}$ (modelo 32002 ), $30 \mathrm{~cm}^{3}$ (modelo 23361 ), e $0,3 \mathrm{~cm}^{3}$ (modelo 31013), da marca PTW e cabos PTW triaxial durante o período de junho de 2013 a fevereiro de 2014 (oito meses).

O teste de fuga consiste na coleta de medidas em um tempo dez vezes maior que o tempo de leitura de uma medição com fonte radioativa. Após este tempo de irradiação com fonte ela é retirada, porém, o equipamento continua medindo e assim é analisado o comportamento ou verificada a variação da leitura no sistema de medida (dosímetro); é analisado se há contagem do tipo corrente ou carga neste tempo de pós-irradiação, determinando-se assim a fuga de corrente existente no equipamento, pois neste momento não está ocorrendo ionização no detector e, assim, esta medição será proveniente de fuga de corrente no circuito (DAMATTO, 2009)

Foi realizado também o teste de fuga de corrente na pré-irradiação, ou seja, após a estabilização do sistema de detecção (sem fonte de radiação) o mesmo é colocado para realizar medições sem estar no feixe de radiação. Para 
tanto, o sistema de detecção não deverá ler nenhum tipo de corrente ou carga, pois não ocorre ionização das moléculas de ar no detector e logo não poderá ter corrente na câmara de ionização. Com isto foi possível observar a variação percentual do conjunto, detector + cabo + eletrômetro, pois foram realizados testes específicos para cada componente. Para a realização do teste foi utilizado uma câmara de ionização, que é padrão secundário, marca PTW, modelo 32002 $\left(1000 \mathrm{~cm}^{3}\right)$ acoplada via cabo triaxial a um eletrômetro padrão secundário PTWUNIDOS (DAMATTO,2009).

Foi sucedido um conjunto de medições a cada 15 dias, onde no intervalo da realização das medidas foi deixado o conjunto de detecção em uma estufa para manter a baixa umidade e a temperatura controladas em aproximadamente $28-30^{\circ} \mathrm{C}$.

Na FIG. 14 são apresentados os resultados dos testes de fuga de corrente realizados no conjunto de deteç̧ão padrão do LCI-IPEN, com o percentual de flutuação estatística das medições pelos dias realizados.

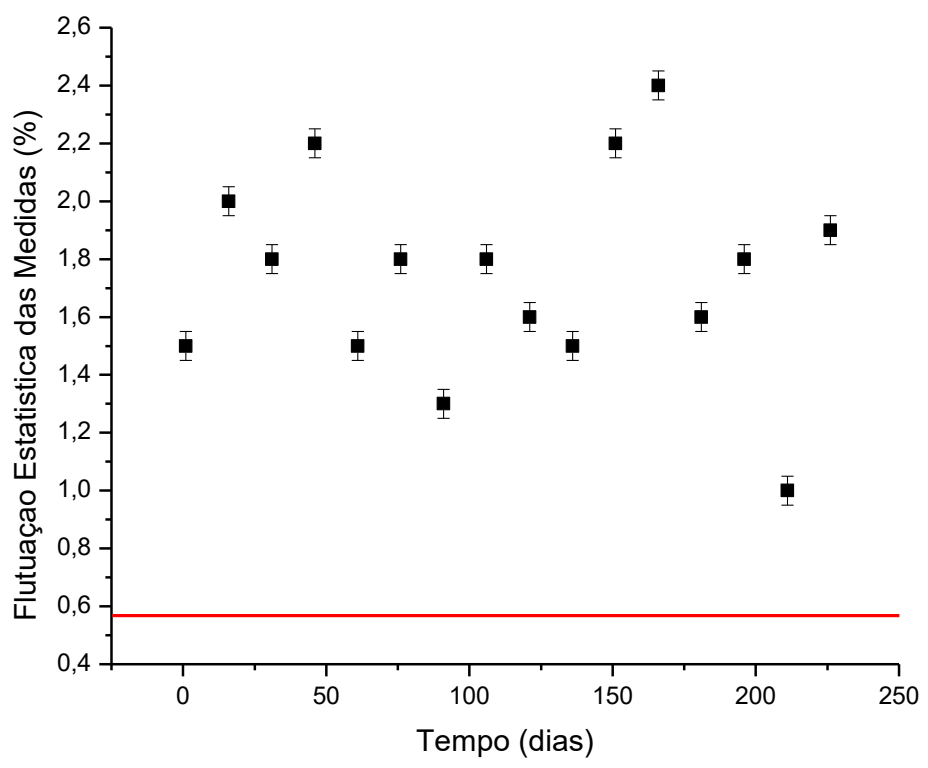

FIGURA 14. Teste de fuga de corrente realizados no conjunto de detecção padrão do LCI-IPEN. A linha vermelha indica o valor máximo aceitável descrito pela IEC 60731 $( \pm 0,58 \%)$

Analisando a FIG. 14 é possível observar os resultados dos testes de fuga de corrente que estão muito acima do valor aceitável descrito pela IEC 60731 
(1997). O valor pré-estabelecido é de uma flutuação estatística de $\pm 0,58 \%$ das medidas realizadas com o conjunto de detecção. Assim, demonstrando que este conjunto não está apto para realizar o processo de dosimetria.

Portanto, foram realizados os testes de fuga de corrente para cada componente especifico. Esta metodologia nos permitiu definir qual componente estava com fuga de corrente, pois foi realizado o teste de fuga de corrente alterando os componentes (detector+cabo+eletrômetro) de um conjunto com de outro conjunto que estava em perfeitas condições de uso (sem fuga de corrente). Na FIG.15 são apresentados os testes realizados variando os componentes do conjunto de detecção para identificar a causa da fuga de corrente.

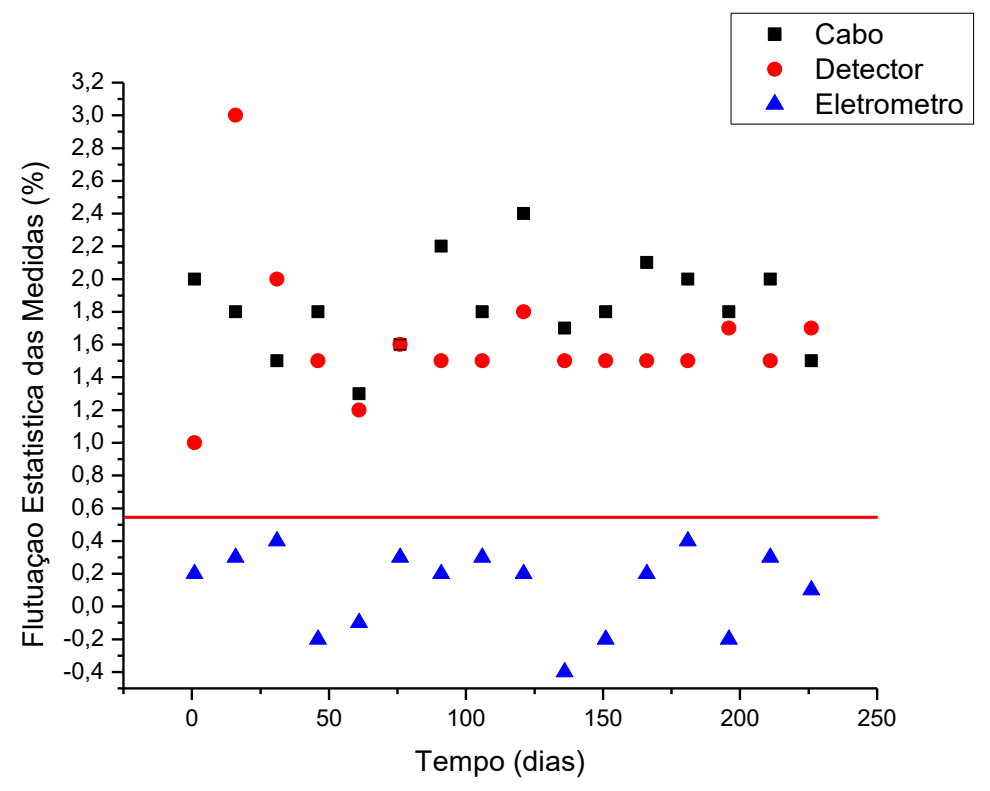

FIGURA 15. Teste de fuga de corrente variando cabo, detector (câmara de ionização) e eletrômetro. A linha vermelha indica o valor máximo aceitável descrito pela IEC 60731 $( \pm 0,58 \%)$

Portanto, conclui-se que o eletrômetro do conjunto de detecção padrão estava com fuga de corrente. Assim, foi realizado o processo de tratamento do eletrômetro PTW, porém não foi obtido êxito para tal. Logo, foi analisada a possibilidade de alterar o conjunto padrão, ou seja, alterando inicialmente o eletrômetro padrão que foi substituido para execução do presente trabalho por um eletrômetro da marca PTW-UNIDOS e que não apresenta fuga de corrente e que permite realizar as medições necessárias neste trabalho como dosimetria dos feixes de radiação de calibração do $\mathrm{LCl}$. As medições foram realizadas 
acrescentando seus devidos parâmetros de incertezas nos fatores e cálculos, que estão descritos nos TECDOC da Agência Internacional de Energia Atômica (IAEA) 1585 (2008) e SRS 16 (2000).

Na FIG. 16 são apresentados os testes de fuga de corrente para o conjunto de detecção composto pela câmara de ionização de volume de $30 \mathrm{~cm}^{3} \mathrm{e}$ eletrômetro PTW-UNIDOS sem fuga de corrente.

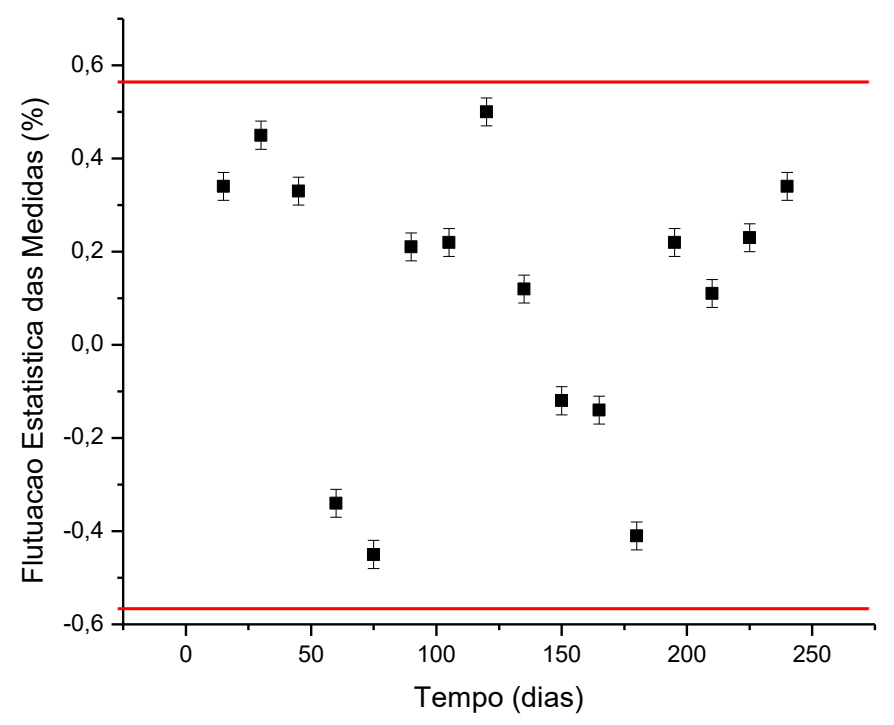

FIGURA 16. Teste de fuga de corrente com o conjunto de detecção composto pela câmara de ionização de volume de $30 \mathrm{~cm}^{3}$ e eletrômetro PTW-UNIDOS sem fuga de corrente. As linhas vermelhas indicam os valores máximo e mínimo aceitável descrito pela IEC $60731( \pm 0,58 \%)$

Portanto, pode-se concluir que o conjunto de detecção composto pela câmara de ionização de volume de $30 \mathrm{~cm}^{3}$ e o eletrômetro PTW-UNIDOS sem fuga de corrente obteve uma variação menor que $\pm 0,58 \%$ (IEC 60731, 1997) estando os valores obtidos dentro do limite de aceitação da norma, desse modo pode-se utilizar o conjunto nas medições.

Na FIG. 17 são apresentados os testes de fuga de corrente para o conjunto de detecção composto pela câmara de ionização de volume de $0,3 \mathrm{~cm}^{3} \mathrm{e}$ eletrômetro PTW-UNIDOS sem fuga de corrente que foi utilizado nos testes de homogeneidade dos feixes de radiações ionizantes dos irradiadores. 


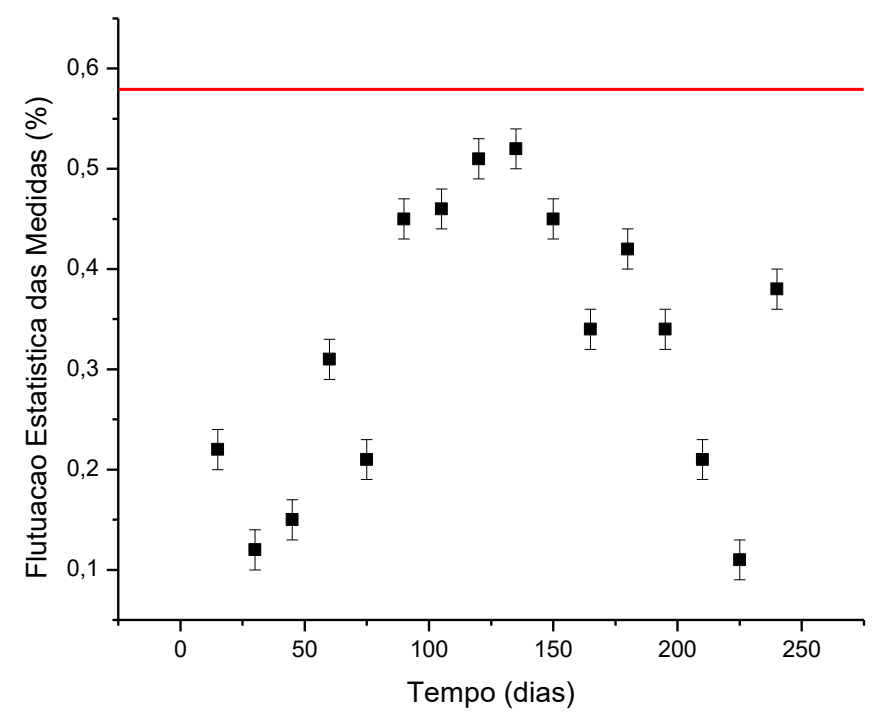

FIGURA 17. Teste de fuga de corrente com o conjunto de detecção composto pela câmara de ionização de volume de $0,3 \mathrm{~cm}^{3}$ e eletrômetro PTW-UNIDOS sem fuga de corrente. A linha vermelha indica o valor máximo aceitável descrito pela IEC 60731 $( \pm 0,58 \%)$

Logo, o conjunto de detecção composto pela câmara de ionização de volume de $0,3 \mathrm{~cm}^{3}$ e eletrômetro PTW-UNIDOS sem fuga de corrente também estavam adequados para as medições, pois os valores obtidos tiveram uma variação menor que $\pm 0,58 \%$ (IEC 60731, 1997) conforme recomendado pela norma.

\subsection{Caracterização do sistema irradiador OB 85/1}

A variação da taxa de kerma no ar com a distância foi realizada com o sistema de detecção de referência para radiação gama do LCI-IPEN com rastreabilidade ao Laboratório Nacional de Metrologia das Radiações lonizantes (LNMRI), calibrado em termos de kerma no ar. Neste caso foi utilizado o eletrômetro sem fuga de corrente para dosimetria dos feixes de radiação de calibração, acrescentando seus devidos parâmetros de incertezas (acréscimo de 0,1\% nos cálculos) que estão descritos nos TECDOC da Agência Internacional de Energia Nuclear (IAEA) 1585 (2008) e SRS 16 (2000). A dosimetria foi realizada em 23/09/2014 e consiste na realização de medidas em quatro pontos do campo de radiação, em intervalos de um metro de distância $(100 \pm 0,05 \mathrm{~cm})$ entre cada ponto (ISO 4037-1, 1996). 
Os valores de kerma no ar apresentado nos gráficos foram obtidos com a equação (5), conforme certificado de calibração do sistema de referência.

$$
K_{a r}=N_{K} \times K_{Q} \times F_{T p} \times L
$$

Onde $N_{K}$ é o coeficiente de calibração, $K_{Q}$ é o fator de correção para a qualidade, $L$ é a leitura do sistema de referência e $F_{T p}$ é fator de correção para as condições ambientais.

Assim, nas FIG. 18,19, 20 e 21 é possível observar o gráfico correspondente a variação da distância da fonte de radiação de ${ }^{137} \mathrm{Cs}$ sem filtro atenuador (distância fonte detector), com um filtro atenuador (distância filtro 1 ao detector), com dois filtros atenuadores (distância filtro 1 e 2, espessuras somadas, ao detector) e com três filtros atenuadores (distância filtro 1, 2 e 3, espessuras somadas, ao detector), respectivamente, com o sistema de detecção de referência.

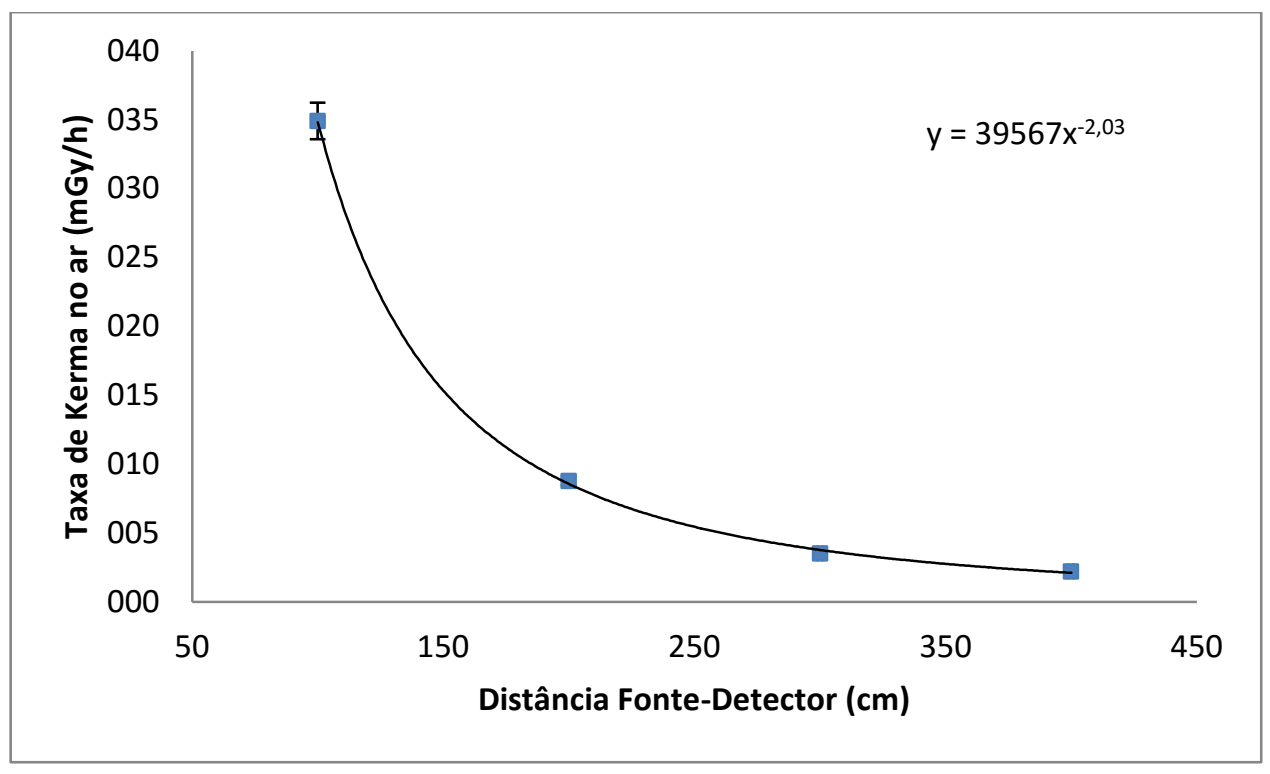

FIGURA 18. Variação da taxa de kerma no ar com a distância com a fonte de radiação de ${ }^{137} \mathrm{Cs}$ sem filtro atenuador ao detector 


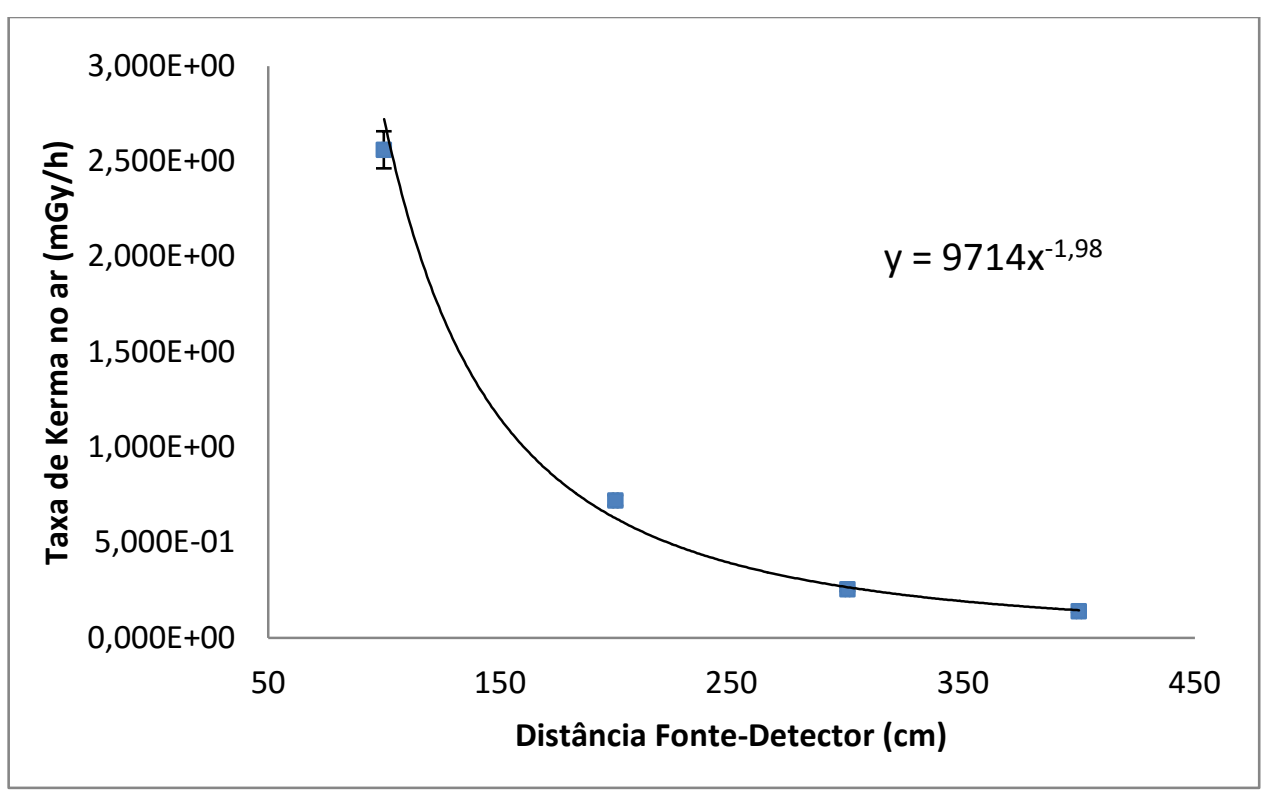

FIGURA 19. Variação da taxa de kerma no ar com a distância com a fonte de radiação de ${ }^{137} \mathrm{Cs}$ com um filtro atenuador ao detector

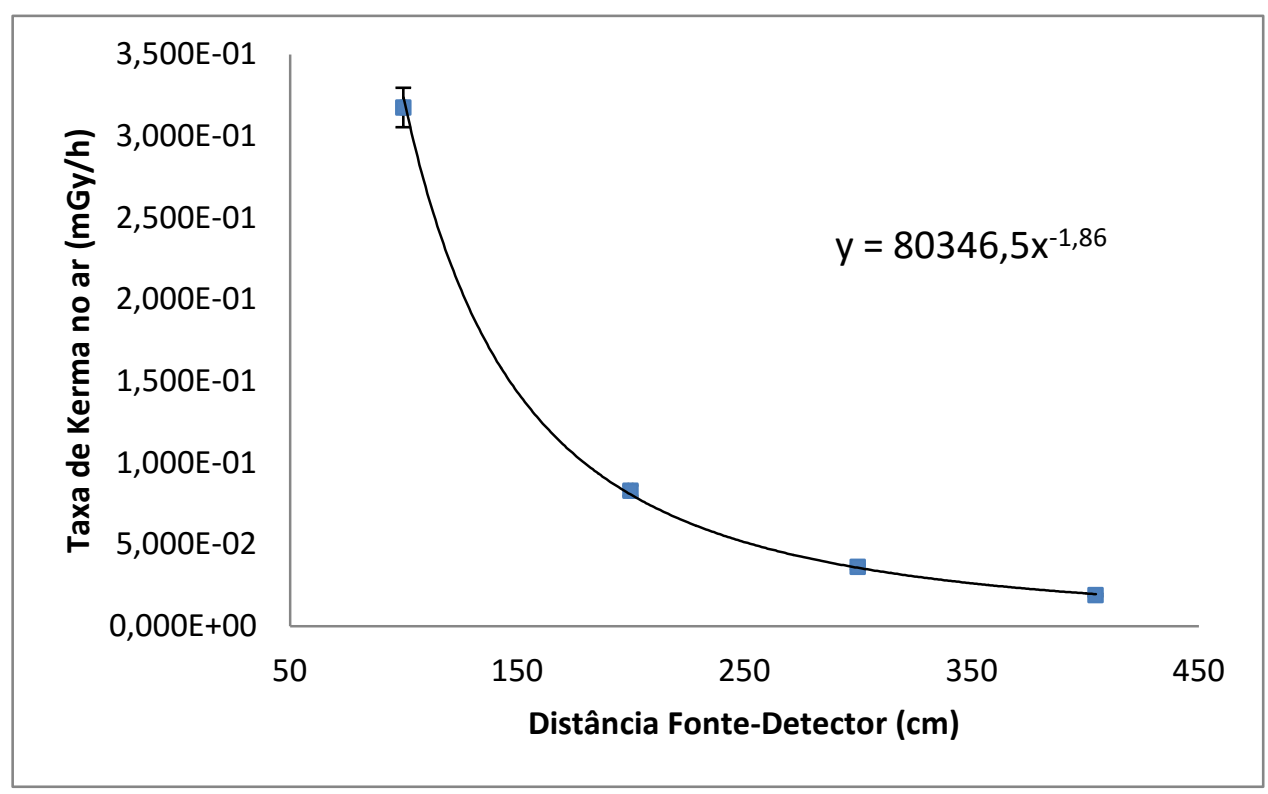

FIGURA 20. Variação da taxa de kerma no ar com a distância com a fonte de radiação de ${ }^{137} \mathrm{Cs}$ com dois filtros atenuadores ao detector 


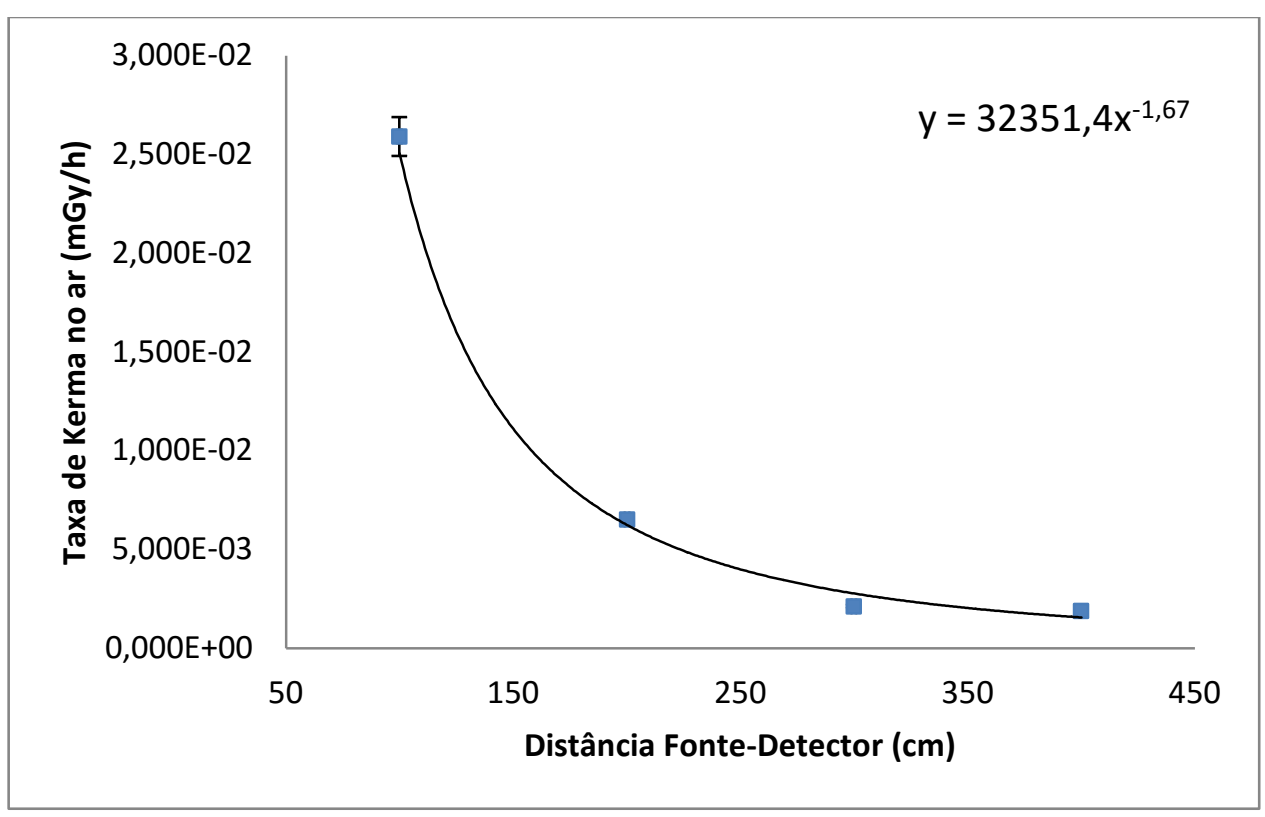

FIGURA 21. Variação da taxa de kerma no ar com a distância com a fonte de radiação de ${ }^{137} \mathrm{Cs}$ com três filtros atenuadores ao detector

Nas Figuras 22, 23, 24 e 25 são apresentados os gráficos correspondentes a dosimetria da fonte de radiação ionizante de ${ }^{60} \mathrm{Co}$ sem filtro atenuador, com um filtro atenuador, com dois filtros atenuadores e com três filtros atenuadores, respectivamente.

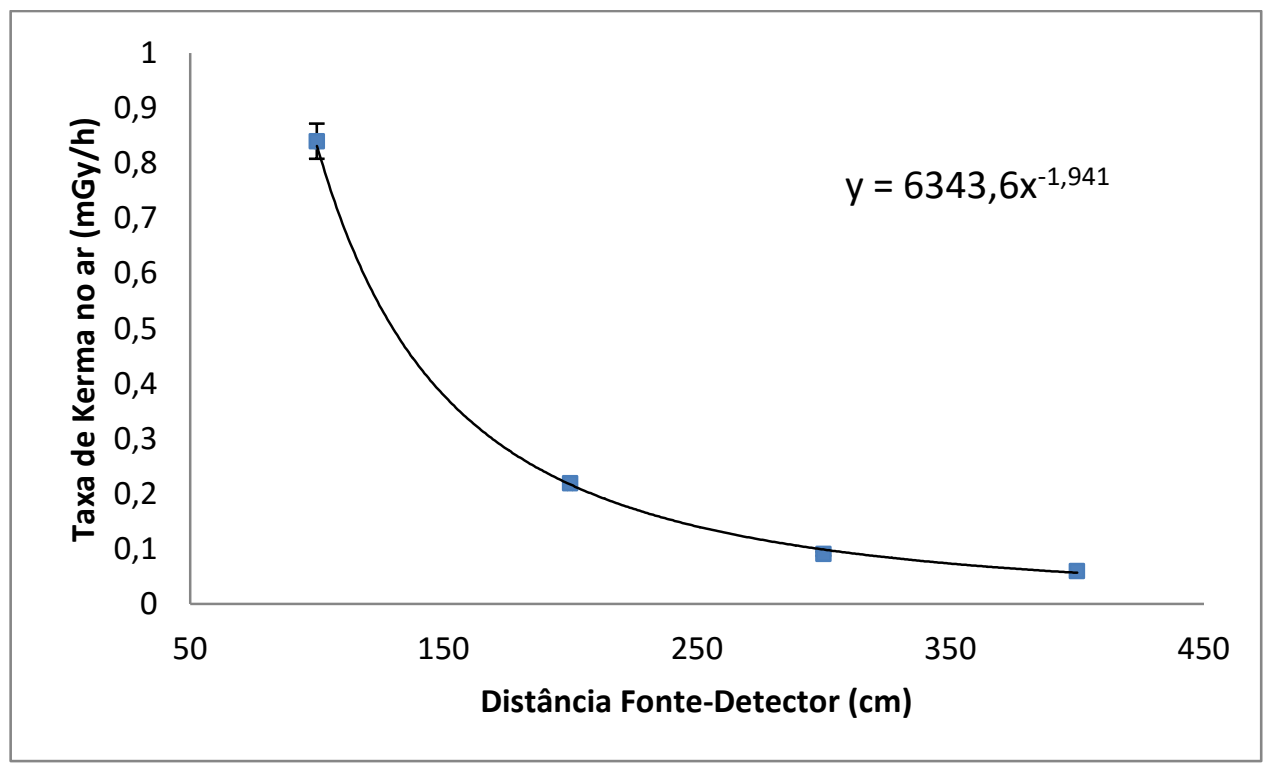

FIGURA 22. Variação da taxa de kerma no ar com a distância com a fonte de radiação de ${ }^{60} \mathrm{Co}$ sem filtro atenuador ao detector 


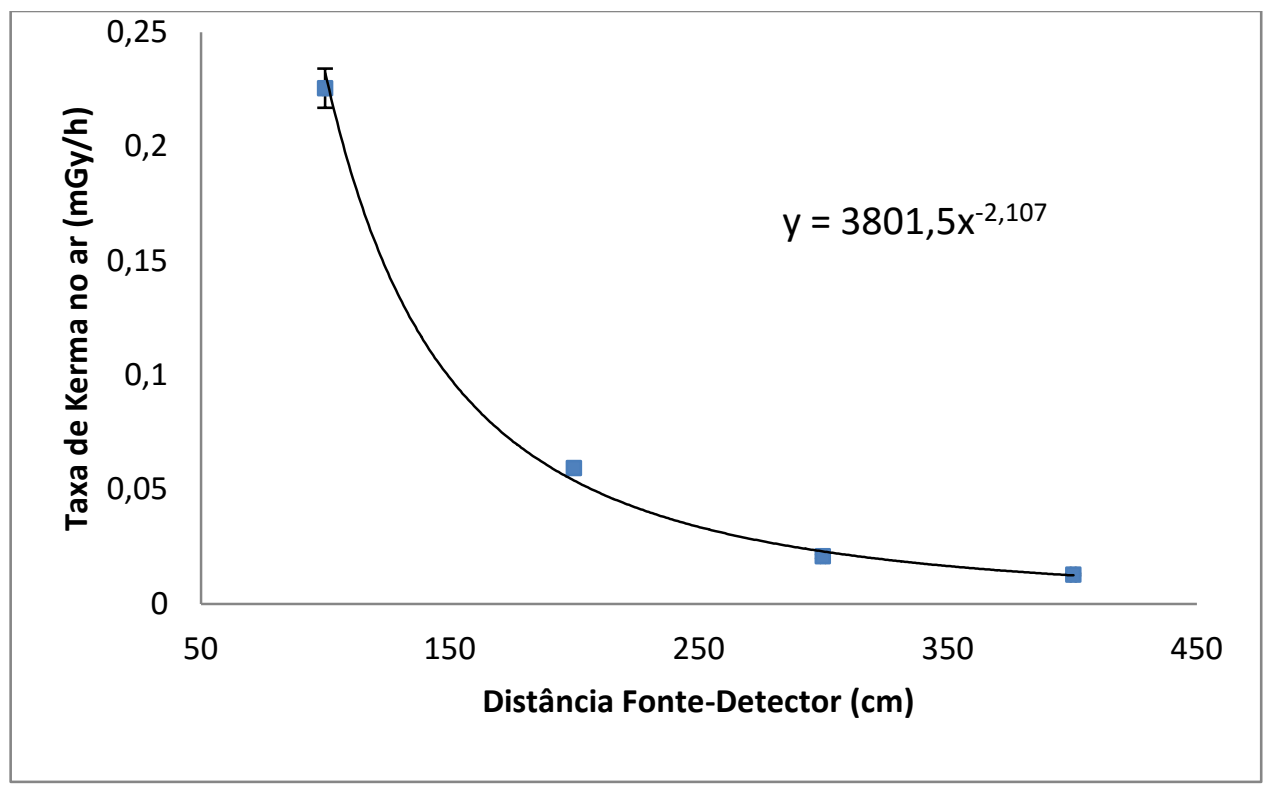

FIGURA 23. Variação da taxa de kerma no ar com a distância com a fonte de radiação de ${ }^{60} \mathrm{Co}$ com um filtro atenuador detector

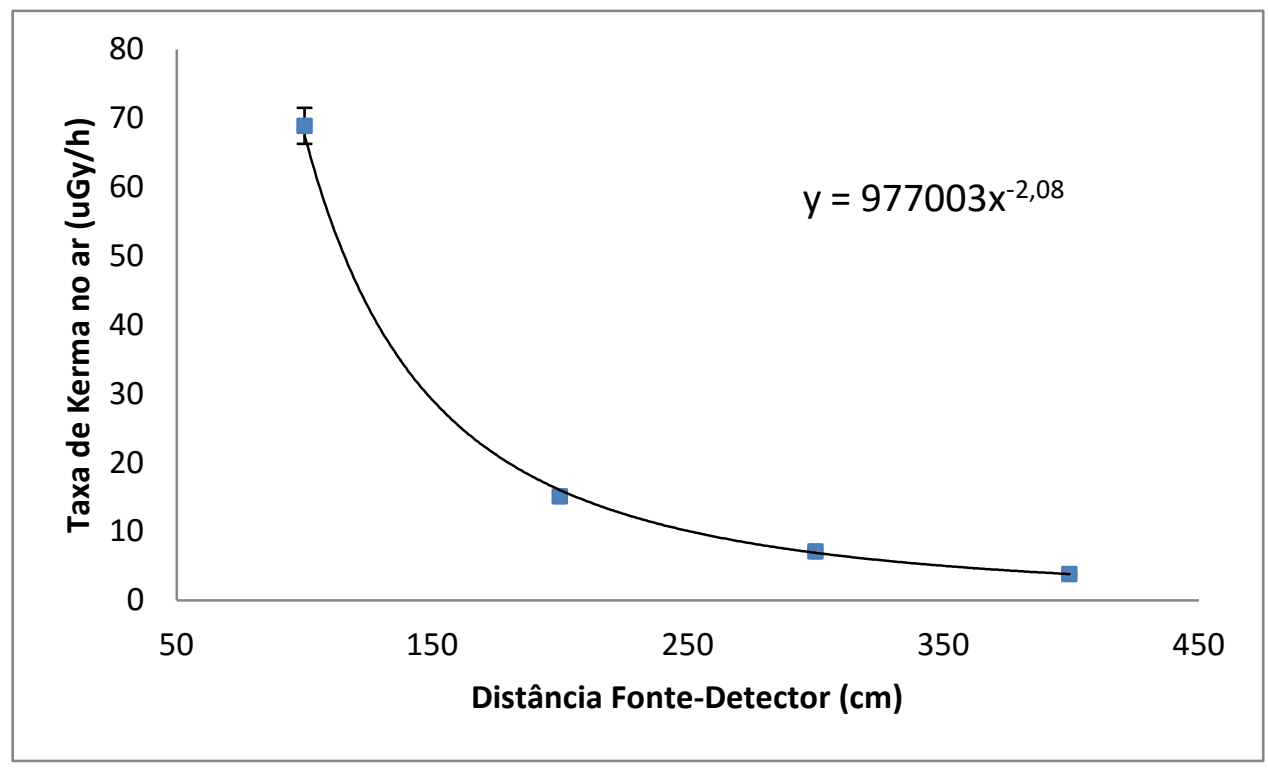

FIGURA 24. Variação da taxa de kerma no ar com a distância com a fonte de radiação de ${ }^{60} \mathrm{Co}$ com dois filtros atenuadores ao detector 


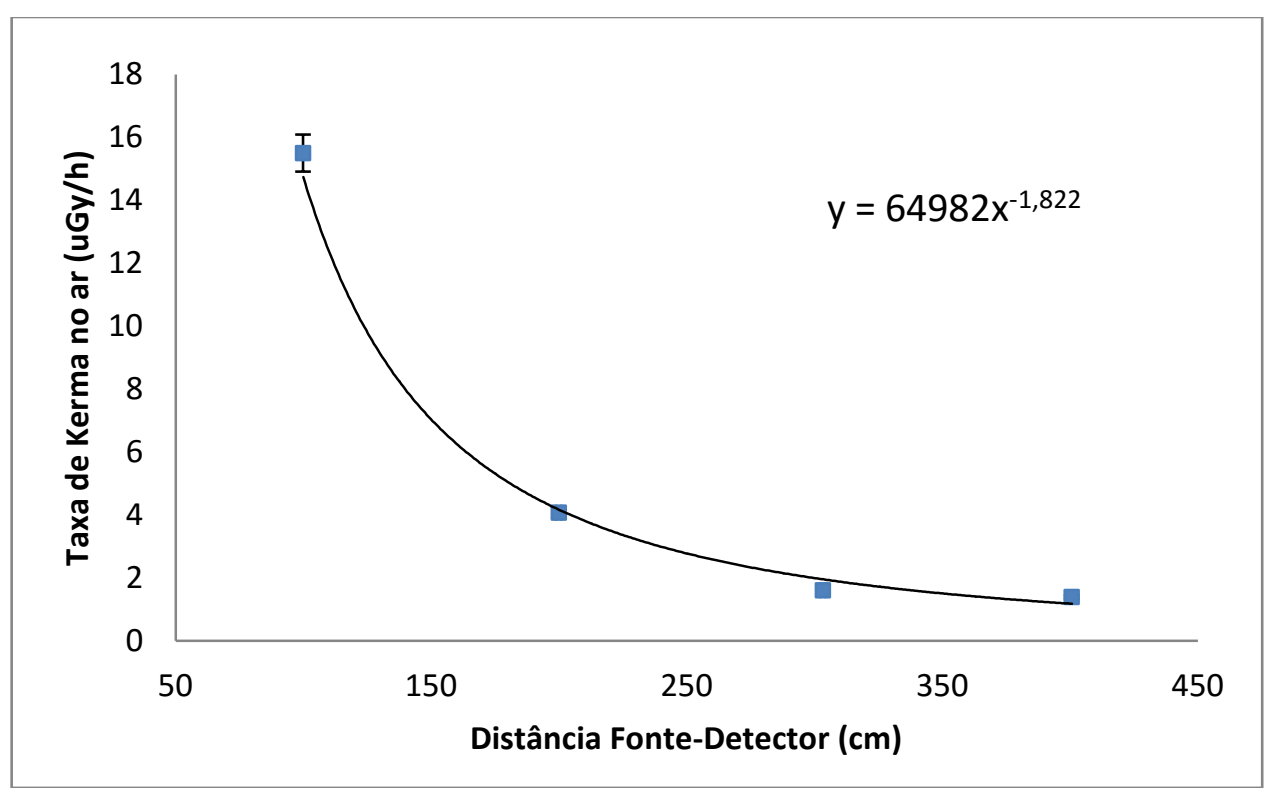

FIGURA 25. Variação da taxa de kerma no ar com a distância com a fonte de radiação de ${ }^{60} \mathrm{Co}$ com três filtros atenuadores ao detector

Portanto, foi possível determinar a variação da taxa de kerma no ar com a distância com as fontes de ${ }^{60} \mathrm{Co}$ e ${ }^{137} \mathrm{Cs}$, porém com a quantidade maior de filtros (FIG. 20) o valor medido se afastava do nominal. Logo, com três filtros foi observado um valor insatisfatório, pois o erro percentual $(\mathrm{e} \%)$ entre o valor nominal e o medido foi de $16,5 \%$. O comportamento da taxa de kerma no ar diminuiu com o inverso da variação do quadrado da distância.

\subsection{Homogeneidade do campo de radiação do irradiador OB/85-1}

Foram realizadas medições nas distâncias de 1,0 e 4,0 metros, com a finalidade de se obter o tamanho experimental do campo útil de radiação, por meio de sua homogeneidade, pois só é possível realizar calibrações e testes na parte homogênea do campo, e esta deve ser maior do que 95\% (ISO/IEC 17025, 2006). Na FIG. 26 é apresentado o gráfico de homogeneidade do campo de radiação nos eixos vertical e horizontal a uma distância de 1,0 $\mathrm{m}$ do centro da fonte de radiação. 


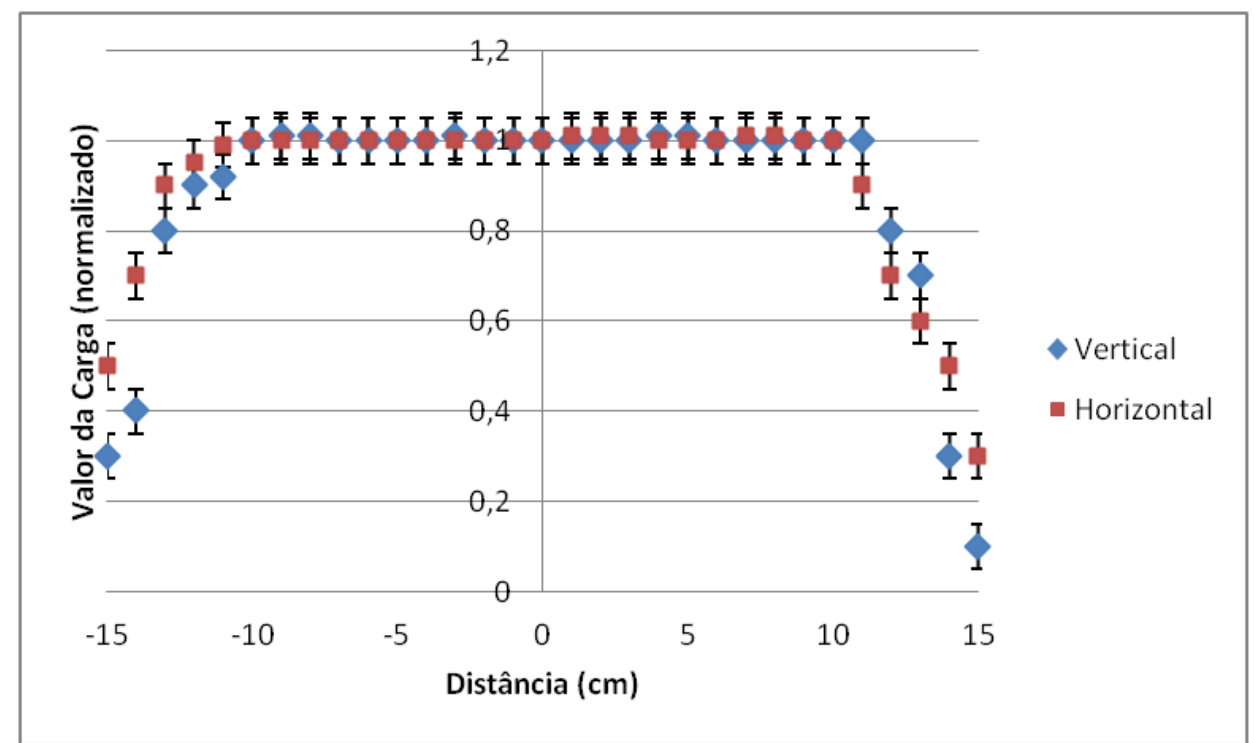

FIGURA 26. Homogeneidade do campo de radiação a 1,0 $\mathrm{m}$ do centro da fonte do irradiador OB85/1

Na FIG. 27 é apresentado o gráfico de homogeneidade do campo de radiação nos eixos vertical e horizontal a uma distância de 4,0 $\mathrm{m}$ do centro da fonte do irradiador.

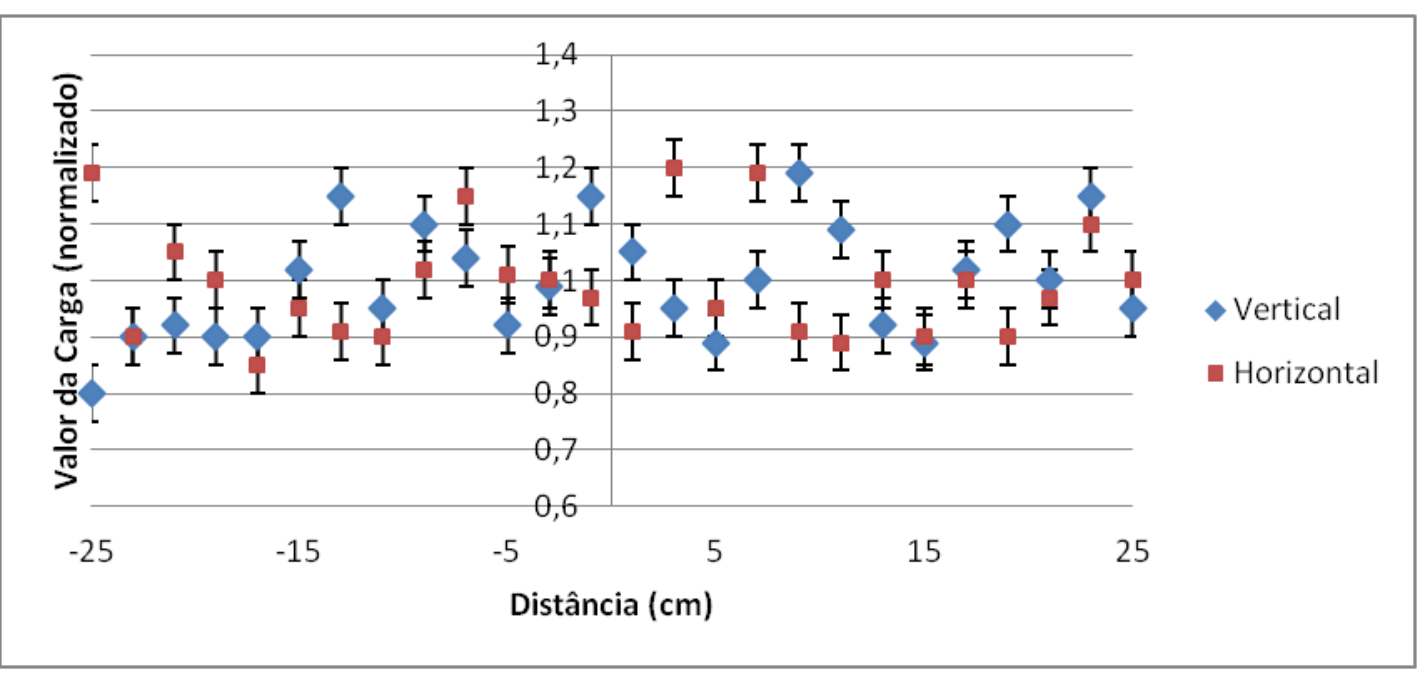

FIGURA 27. Homogeneidade do campo de radiação a 4,0 m do centro do irradiador OB85/1

Verifica-se uma homogeneidade acima de $95 \%$ nos dois casos, estando de acordo com as recomendações (ISO/IEC 17025, 2006). 


\subsection{Caracterização do sistema do Irradiador Caesa-Gammatron}

A dosimetria neste irradiador foi realizada utilizando o sistema dosimétrico de referência para radiação gama do Laboratório de Calibração de Instrumentos do Instituto de Pesquisas Energéticas e Nucleares (LCI-IPEN) com rastreabilidade ao Laboratório Nacional de Metrologia das Radiações lonizantes (LNMRI), calibrado em termos de kerma no ar com uma incerteza de 1,8\% (k=2). É recomendado que a dosimetria fosse realizada em intervalos de aproximadamente um ano pelo LCl.

São realizadas medições em quatro pontos do campo de radiação, em intervalos de um metro de distância entre cada ponto, depois é confeccionado um gráfico com ajuste. Essas medições foram realizadas para todas as condições de uso do sistema irradiador, ou seja, sem filtro e com um filtro. No caso da utilização de atenuador, a distância foi medida a partir do último atenuador, seguindo as recomendações da Norma ISO 4037.

Essa dosimetria foi realizada em 22/05/2015, na FIG. 28, é apresentado o gráfico e seu respectivo ajuste para medições realizadas com intervalos de $100,00 \pm 0,05 \mathrm{~cm}$, sem filtro atenuador.

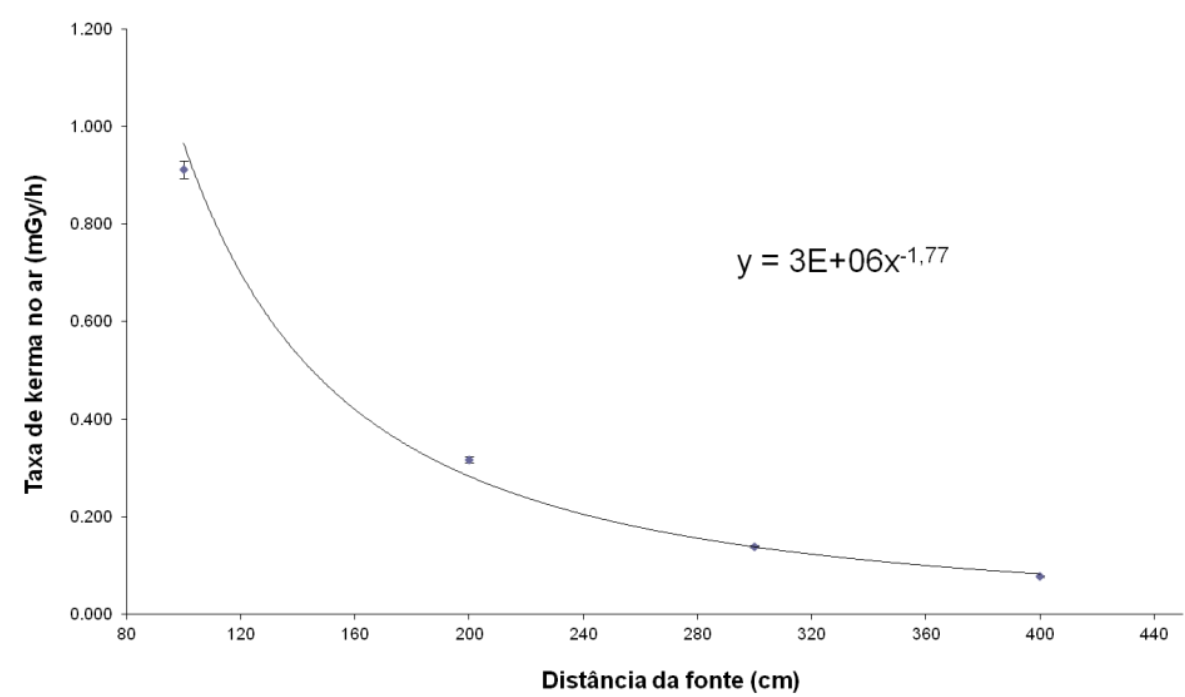

FIGURA 28. Variação da taxa de kerma no ar com a distância a fonte de ${ }^{137}$ Cs realizada sem filtro atenuador ao detector

Na FIG. 29 é aprentado o gráfico e seu respectivo ajuste para medições realizadas com intervalos de 100,00 $\pm 0,05 \mathrm{~cm}$, com um filtro atenuador. 


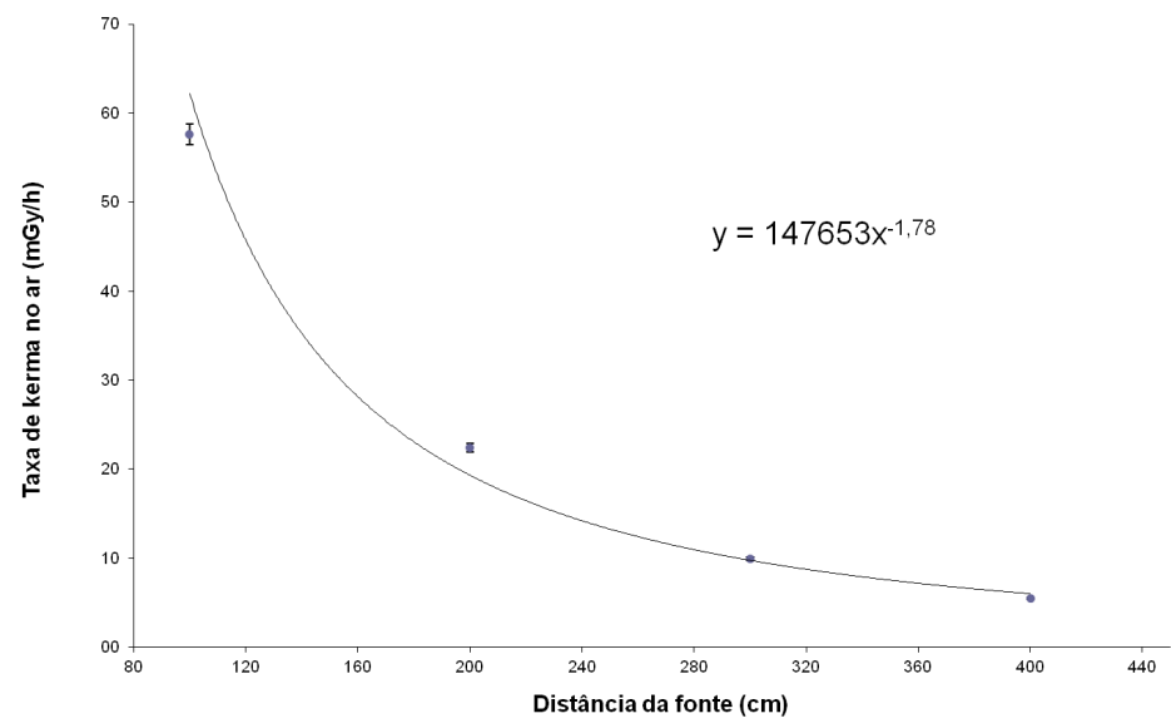

FIGURA 29. Variação da taxa de kerma no ar com a distância a fonte de ${ }^{137}$ Cs realizada com um filtro atenuado ao detector

\subsection{Homogeneidade do Campo de Radiação do Irradiador Caesa-Gammatron}

Essas medições foram realizadas a uma distância de $1,0 \mathrm{~m}$ e a 4,0 $\mathrm{m}$ da fonte de radiação, com o objetivo de determinar o tamanho do campo útil para calibrações e testes em geral, nos limites de utilização do banco óptico. Na FIG. 30 é aprentado o gráfico de homogeneidade do campo de radiação nos eixos vertical e horizontal a uma distância de 1,0 m.

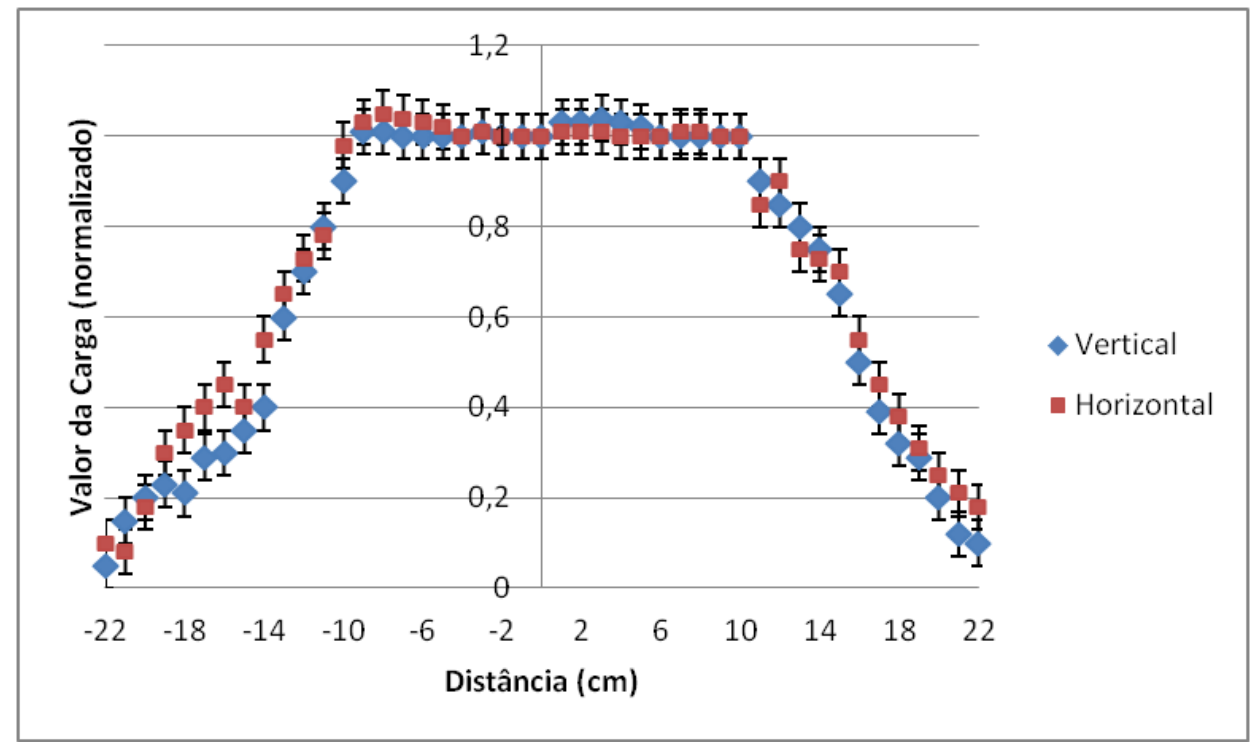

FIGURA 30. Homogeneidade do campo de radiação a 1,0 m do irradiador CaesaGammatron 
Na FIG. 29 é apresentado o gráfico de homogeneidade do campo de radiação nos eixos em vertical e horizontal a uma distância de 4,0 m.

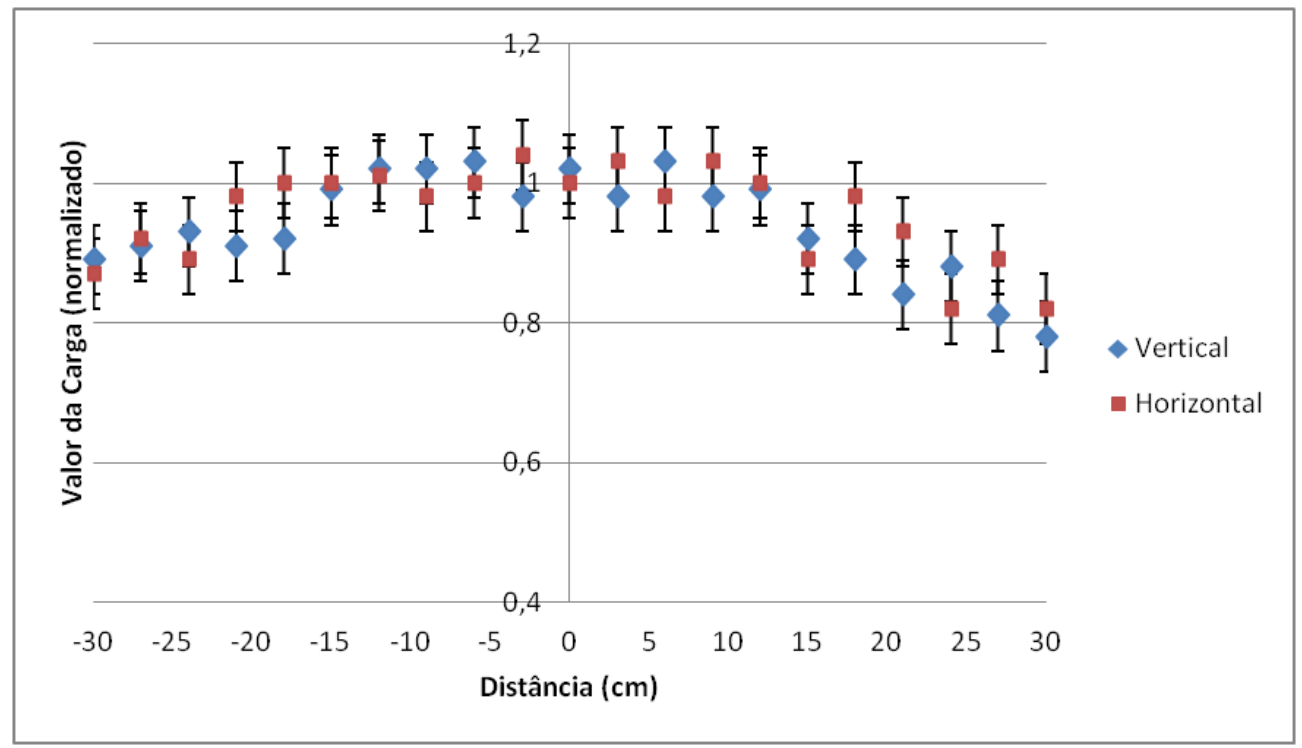

FIGURA 31. Homogeneidade do campo de radiação a 4,0 m do irradiador CaesaGammatron

Verificou-se uma homogeneidade acima de 95\% nos dois casos, estando de acordo com as recomendações (ISO/IEC 17025, 2006).

\subsection{Estudo dos sistemas de detecção de alta taxa de kerma no ar}

Os monitores portáteis de radiação são largamente utilizados na monitoração de áreas controladas e supervisionadas, sendo seu emprego de grande valia para as tarefas e rotinas realizadas nestas áreas. A confiabilidade das medidas realizadas pelos equipamentos é essencial para a segurança física dos usuários dos instrumentos e do patrimônio, assim como para o meio ambiente.

Desse modo se faz necessário o estabelecimento de um procedimento rotineiro de verificação das condições operacionais dos instrumentos, principalmente os monitores portáteis que são utilizados na monitoração de áreas controladas e que possuem altas taxas de exposição, de modo a garantir a qualidade das medidas realizadas pelo equipamento.

A verificação das características operacionais dos monitores portáteis de radiação é realizada por meio de testes de desempenho. Estes testes podem ser entendidos como um conjunto de procedimentos (testes) que permitem avaliar as 
condições operacionais dos equipamentos.

O teste de desempenho pode incluir a avaliação de algumas ou de todas as características dos monitores portáteis de radiação. As características operacionais são divididas em características radiológicas e não radiológicas.

As características não radiológicas principais em geral testadas são:

- Variação da leitura do equipamento com a tensão das baterias;

- Efeito de geotropismo;

- Deriva de zero elétrico.

Características radiológicas frequentemente testadas:

- Dependência energética;

- Dependência angular;

- Resposta a outras radiações ionizantes;

- Erro intrínseco da leitura do equipamento;

- Estouro de escala ou saturação, também denominado ensaio de segurança.

Os testes que foram realizados neste trabalho foram: variação da leitura do equipamento com a tensão das baterias; dependência energética; dependência angular; estouro de escala ou saturação; com um dos principais detectores de radiação ionizante de alta taxa de exposição utilizados, ou o Automess Teletector modelo 6150.

\subsubsection{Variação da leitura do equipamento com a tensão}

Os detectores Automess Teletector são instrumentos portáteis; deve-se ter cuidados especiais com as baterias que fornecem a energia elétrica necessária para o seu funcionamento pleno. Portanto, se as tensões das baterias estiverem abaixo do necessário para o seu funcionamento teremos medidas sem confiabilidade.

Assim, foi realizado o teste de variação de leitura do equipamento com a tensão trocando apenas umas das baterias do equipamento por outra com tensão inferior ao recomendado pelo fabricante e se obteve valores qualitativos. Não foi possível ensaiar muitos equipamentos para se obter valores quantitativos, 
segundo recomendado pela norma ABNT NBR 10011 (1987), pois a maioria destes detectores ainda estavam no processo de calibração do LCl.

$\mathrm{Na}$ TAB. 1 são apresentados os detectores do tipo teletector que foram representados por $\mathrm{T}$, o valor de taxa de exposição obtida com as baterias em perfeito estado de uso (tensão nominal), o valor de taxa de exposição obtida com as baterias com tensão inferior ao usual, e a diferença percentual entre as respectivas medições. As medições foram realizadas com a fonte de radiação ionizante de ${ }^{137} \mathrm{Cs}$ do irradiador OB85/1, com valor de taxa de exposição fixado em $30,4 \mathrm{mR} / \mathrm{h}$ e todos os detectores ensaiados foram calibrados antes da realização do teste.

TABELA 1. Medidas de taxa de exposição com diferentes detectores de modelo teletector com diferentes tensões aplicadas (baterias com tensão nominal e com tensão abaixo do nominal).

\begin{tabular}{|cccc|} 
Teletector & \multicolumn{2}{c}{ Taxa de exposição $(\mathbf{m R / h})$} & $\begin{array}{c}\text { Diferença } \\
\text { Tensão usual }\end{array}$ \\
\hline $\mathbf{T}_{\mathbf{1}}$ & 30,0 & 25,9 & $14 \%$ \\
\hline $\mathbf{T}_{\mathbf{2}}$ & 30,7 & 28,1 & $8 \%$ \\
\hline $\mathbf{T}_{\mathbf{3}}$ & 29,9 & 24,1 & $19 \%$ \\
\hline $\mathbf{T}_{\mathbf{4}}$ & 30,1 & 26,9 & $11 \%$ \\
\hline $\mathbf{T}_{\mathbf{5}}$ & 31,0 & 28,3 & $9 \%$ \\
\hline $\mathbf{T}_{\mathbf{6}}$ & 29,7 & 25,2 & $15 \%$ \\
\hline $\mathbf{T}_{\mathbf{7}}$ & 30,1 & 26,6 & $12 \%$ \\
\hline $\mathbf{T}_{\mathbf{8}}$ & 30,6 & 22,9 & $25 \%$ \\
\hline $\mathbf{T}_{\mathbf{9}}$ & 29,8 & 27,0 & $9 \%$ \\
\hline $\mathbf{T}_{\mathbf{1 0}}$ & 30,7 & 25,8 & $16 \%$ \\
\hline
\end{tabular}

Pode-se visualizar nesta TAB. uma diferença percentual variando de $9 \%$ a $25 \%$ do valor medido com bateria e tensão nominal e, tensão abaixo do valor nominal. Em média o valor da tensão da bateria estava abaixo do valor nominal em 0,5 V (apenas umas delas), as outras baterias estavam com tensão nominal ou a tensão da bateria de $9 \mathrm{~V}$ estava abaixo do nominal. Assim, mesmo com a tensão da baterias abaixo do nominal em caso o que foi importante para determinação da tensão abaixo foi que o equipamento não apresentava em seu 
display a informação ao usuário de tensão baixa. Logo, podemos concluir que é muito importante a verificação periódica da tensão das baterias, pois apenas uma delas com tensão inferior a nominal já pode apresentar um diferença de até $25 \%$ no valor da medição, conforme constatado.

\subsubsection{Dependência angular}

A indicação à radiação incidente pode se alterar com a mudança de ângulo de direção formada entre o elemento detector e o feixe de radiação incidente em seu volume sensível. Devem ser realizados testes e verificações periódicas da dependência angular dos detectores portáteis, para maior garantia das medições.

O monitor portátil teletector foi posicionado no banco de calibração, e na posição de calibração, ou seja, com o feixe de raios gama incidindo sobre toda a sonda detectora atingindo o centro geométrico do elemento detector; nesta situação os equipamentos se encontram sobre a mesa de calibração no plano horizontal (paralelos à superfície da mesa), sendo esta a posição adotada como de ângulo $0^{\circ}$. As medidas foram realizadas com a taxa de exposição fixada em $50 \mathrm{mR} / \mathrm{h}$ proveniente da fonte de radiação de ${ }^{137} \mathrm{Cs}$ do irradiador OB85/1.

$\mathrm{Na}$ TAB. 2 são apresentados os resultados obtidos para o teste de dependência angular e na FIG. 32 é apresentado o teste de dependência angular. Nesta TAB. São apresentados os detectores teletector representados por T, o valor de taxa de exposição ( $\mathrm{mR} / \mathrm{h}$ ) nas posições de $0^{\circ}$ (adotada para calibração), direita e esquerda $45^{\circ}$ (inclinado em relação a posição de calibração) e perpendicular a fonte de radiação (“apontando” para fonte de radiação) $90^{\circ}$. 

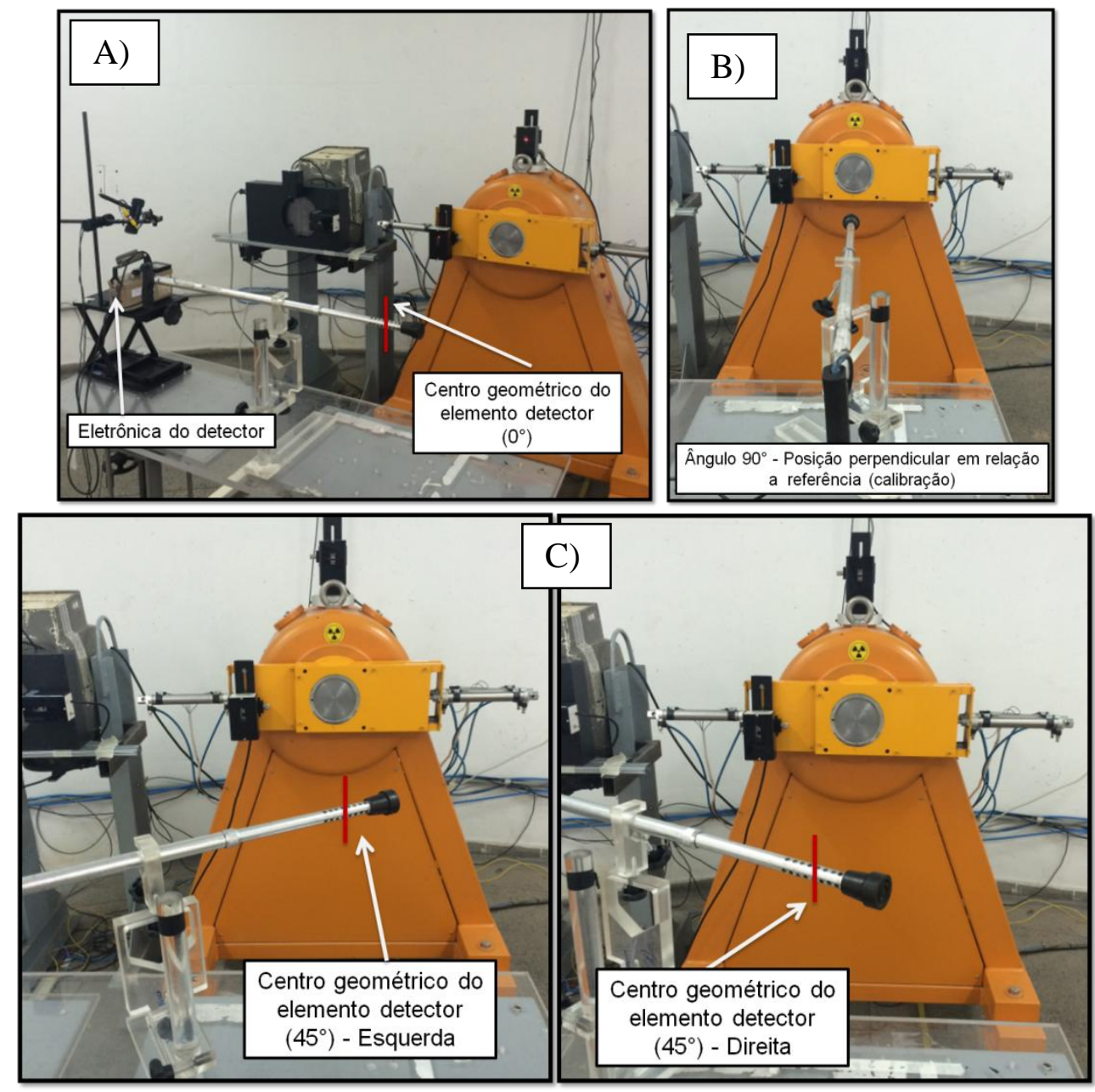

FIGURA 32. Arranjo experimental para realização do teste de dependência angular: A) $0^{\circ}$; B) $90^{\circ}$; C) $45^{\circ}$ (esquerda e direita)

TABELA 2. Medidas de dependência angular dos teletectors.

\begin{tabular}{|c|c|c|c|c|c|c|c|c|c|}
\hline \multirow[b]{2}{*}{ Teletector } & \multicolumn{8}{|c|}{ Taxa de Exposição (mR/h) } & \multirow{2}{*}{$\begin{array}{c}\text { Diferença das } \\
\text { Medidas } \\
0^{\circ} \text { e } 90^{\circ}(\%)\end{array}$} \\
\hline & $\begin{array}{c}\text { Posição } \\
0^{\circ}\end{array}$ & $\pm \sigma$ & $\begin{array}{c}\text { Direita } \\
45^{\circ}\end{array}$ & $\pm \sigma$ & $\begin{array}{c}\text { Esquerda } \\
45^{\circ}\end{array}$ & $\pm \sigma$ & $\begin{array}{c}\text { Perpendicular } \\
90^{\circ}\end{array}$ & $\pm \sigma$ & \\
\hline $\mathrm{T}_{1}$ & 49,8 & 0,8 & 41,0 & 0,7 & 42,0 & 0,6 & 11,3 & 0,2 & $77 \%$ \\
\hline $\mathrm{T}_{2}$ & 49,4 & 0,8 & 42,0 & 0,8 & 42,2 & 0,6 & 12,5 & 0,2 & $75 \%$ \\
\hline$T_{3}$ & 49,5 & 0,8 & 41,5 & 0,8 & 41,1 & 0,6 & 15,1 & 0,3 & $69 \%$ \\
\hline $\mathrm{T}_{4}$ & 49,2 & 0,7 & 43,7 & 0,8 & 43,9 & 0,7 & 13,2 & 0,2 & $73 \%$ \\
\hline$T_{5}$ & 49,3 & 0,7 & 43,2 & 0,8 & 41,2 & 0,6 & 14,3 & 0,3 & $71 \%$ \\
\hline$T_{6}$ & 49,9 & 0,8 & 43,8 & 0,8 & 41,8 & 0,6 & 8,2 & 0,2 & $84 \%$ \\
\hline $\mathrm{T}_{7}$ & 49,2 & 0,7 & 41,9 & 0,8 & 43,9 & 0,7 & 12,5 & 0,2 & $75 \%$ \\
\hline$T_{8}$ & 49,3 & 0,7 & 41,1 & 0,7 & 41,8 & 0,6 & 17,9 & 0,3 & $64 \%$ \\
\hline$T_{9}$ & 50,0 & 0,8 & 42,3 & 0,8 & 43,3 & 0,7 & 16,2 & 0,3 & $68 \%$ \\
\hline$T_{10}$ & 49,3 & 0,7 & 41,5 & 0,8 & 41,0 & 0,6 & 5,1 & 0,1 & $90 \%$ \\
\hline
\end{tabular}


Os valores obtidos no teste de dependência angular para a posição perpendicular $90^{\circ}$ foram de $64 \%$ a $90 \%$ do valor para o ângulo de $0^{\circ}$. Segundo a norma IEC 395 (1972) a indicação à radiação incidente, segundo um ângulo não superior a $45^{\circ}$ com relação à direção de calibração, não deve ser menor do que $80 \%$, da indicação obtida segundo a direção de calibração; para um ângulo máximo de $90^{\circ}$, a indicação não deve ser menor do que 50 \% da indicação obtida segundo a direção de calibração.

Portanto, os detectores de modelo teletector obtiveram valores satisfatórios para as medidas realizadas a $45^{\circ}$, pois as variações não chegaram a $20 \%$, e para as medidas de $90^{\circ}$ os valores não foram satisfatórios para nenhum dos detectores testados, todos os equipamento apresentaram variação maior que $50 \%$. Assim, foi demonstrado a importância do cuidado da realização das medições deste equipamento em suas rotinas, sendo necessário realizar medições em diferentes direções para obter-se a medição mais próxima da nominal.

Nos manuais de operação e de instruções dos equipamentos não consta nenhuma informação sobre a resposta dos mesmos para este tipo de ensaio.

\subsubsection{Dependência energética}

A dependência energética de um monitor portátil de radiação pode ser definida como a variação na resposta do instrumento em função da energia da radiação para um mesmo tipo de radiação e taxa de dose absorvida referenciada ao tecido ou no ar, e em princípio, para todo o intervalo de energias em que o equipamento foi projetado para medir. Deve-se manter 0 valor da taxa de exposição constante(ABNT NBR 10011, 1987).

Os detectores tipo teletector foram submetidos à radiação gama de fontes de ${ }^{60} \mathrm{Co}$ e ${ }^{137} \mathrm{Cs}$ provenientes do irradiador OB 85 , devidamente alinhado com o sistema de posicionamento do equipamento. A distância entre a fonte de radiação e o equipamento foi de $1,0 \mathrm{~m}$, mantendo o centro do elemento detector sempre alinhado com o feixe de radiação. A taxa de exposição utilizada para realização do teste de dependência energética foi de $50 \mathrm{mR} / \mathrm{h}$ tanto para fonte de ${ }^{60} \mathrm{Co}$ e a de ${ }^{137} \mathrm{Cs}$ (irradiador OB85/1).

$\mathrm{Na}$ TAB. 3 são apresentados os detectores teletector que foram 
representados por $\mathrm{T}$, os valores de taxa de exposição medidas pelo teletector das fontes de radiação ionizante ${ }^{60} \mathrm{Co}$ e ${ }^{137} \mathrm{Cs}$, e os valores de taxa de exposição no ar fornecidas pela dosimetria do sistema de calibração do LCI das fontes de radiação ionizante ${ }^{60} \mathrm{Co}$ e ${ }^{137} \mathrm{Cs}$ com suas respectivas incertezas associadas. Para a análise foi determinado a diferença percentual entre as respectivas medidas.

TABELA 3. Medidas de taxa de exposição com diferentes detectores do tipo teletector com fontes de ${ }^{60} \mathrm{Co} \mathrm{e}{ }^{137} \mathrm{Cs}$

\begin{tabular}{|c|c|c|c|c|c|c|c|c|c|}
\hline \multirow[b]{2}{*}{ Teletector } & \multicolumn{8}{|c|}{ Taxa de exposição (mR/h) } & \multirow[b]{2}{*}{$\begin{array}{c}\text { Diferença das } \\
\text { Medidas (\%) }\end{array}$} \\
\hline & $\begin{array}{c}{ }^{137} \mathrm{Cs} \\
\text { "nominal" }\end{array}$ & $\pm \sigma$ & $\begin{array}{l}{ }^{137} \mathrm{Cs} \\
\text { medida }\end{array}$ & $\pm \sigma$ & $\begin{array}{c}{ }^{60} \mathrm{Co} \\
\text { "nominal" }\end{array}$ & $\pm \sigma$ & ${ }^{60} \mathrm{Co}$ & $\pm \sigma$ & \\
\hline $\mathrm{T}_{1}$ & 50,0 & 0,8 & 49,1 & 0,9 & 50,0 & 0,8 & 68,9 & 1,3 & $40 \%$ \\
\hline $\mathrm{T}_{2}$ & 50,0 & 0,8 & 49,5 & 0,9 & 50,0 & 0,8 & 69,0 & 1,3 & $39 \%$ \\
\hline$T_{3}$ & 50,0 & 0,8 & 49,4 & 0,9 & 50,0 & 0,8 & 71,5 & 1,3 & $45 \%$ \\
\hline $\mathrm{T}_{4}$ & 50,0 & 0,8 & 49,5 & 0,9 & 50,0 & 0,8 & 65,2 & 1,2 & $32 \%$ \\
\hline $\mathrm{T}_{5}$ & 50,0 & 0,8 & 49,8 & 0,9 & 50,0 & 0,8 & 66,2 & 1,2 & $33 \%$ \\
\hline$T_{6}$ & 50,0 & 0,8 & 49,9 & 0,9 & 50,0 & 0,8 & 68,4 & 1,3 & $37 \%$ \\
\hline $\mathrm{T}_{7}$ & 50,0 & 0,8 & 49,4 & 0,9 & 50,0 & 0,8 & 69,4 & 1,3 & $40 \%$ \\
\hline $\mathrm{T}_{8}$ & 50,0 & 0,8 & 50,0 & 0,9 & 50,0 & 0,8 & 67,8 & 1,3 & $36 \%$ \\
\hline$T_{9}$ & 50,0 & 0,8 & 49,3 & 0,9 & 50,0 & 0,8 & 69,2 & 1,3 & $40 \%$ \\
\hline $\mathrm{T}_{10}$ & 50,0 & 0,8 & 49,2 & 0,9 & 50,0 & 0,8 & 68,6 & 1,3 & $39 \%$ \\
\hline
\end{tabular}

Portanto, observou-se que o detector de radiação tipo teletector possuia dependência energética, pois houve uma diferença nas medições de taxa de exposição das fontes de ${ }^{60} \mathrm{Co}$ e ${ }^{137} \mathrm{Cs}$ entre $33 \%$ a $45 \%$. Assim, verificou-se também que com as leituras de ${ }^{137} \mathrm{Cs}$ as medições ficaram mais próximas do valor convencional ou de referência (obtido na dosimetria), considerando ainda a incerteza nas medições. As medições com fonte de ${ }^{60} \mathrm{Co}$ ficaram fora do valor de referência (dosimetria), mesmo considerando a incerteza nas medições.

De acordo com a norma ABNT NBR 10011 (1987) a indicação do instrumento para radiações com energias entre $50 \mathrm{keV}$ e $3 \mathrm{MeV}$ não deve diferir em $\pm 25 \%$ dentro deste intervalo de energias. Logo, todos os equipamentos se apresentaram fora do recomendado pela norma, porém os equipamentos estavam dentro das especificações descritas pelo fabricante em seu manual, ou seja, dependência energética de $\pm 50 \%$. 


\subsubsection{Estouro de escala ou saturação}

O teste de estouro de escala ou saturação faz parte dos ensaios denominados de "Condições de Segurança". Para taxas de exposição correspondendo as indicações acima do limite superior de qualquer faixa nominal, o mostrador do instrumento deve acusar estouro de escala (BITELLI, 1982; KNOLL, 2000).

Neste ensaio foi utilizado o irradiador Hopewell com a fonte de ${ }^{137} \mathrm{Cs}$, onde os instrumentos foram submetidos a taxas de exposição 10 vezes maiores que os respectivos fundos de escala por cerca de 5 minutos, ou seja, uma taxa de exposição maior que 10 Sv/h (BITELLI, 1982; KNOLL, 2000).

$\mathrm{Na}$ TAB. 4 são apresentados os resultados dos ensaios de estouro de escala dos detectores portáteis de radiação ensaiados.

TABELA 4. Ensaios de estouro de escala de monitores portáteis do tipo Geiger- Müller (Teletectors).

\begin{tabular}{|c|c|}
\hline Teletector & Resultado \\
\hline $\mathrm{T}_{1}$ & Aprovado \\
\hline $\mathrm{T}_{2}$ & Aprovado \\
\hline $\mathrm{T}_{3}$ & Aprovado \\
\hline $\mathrm{T}_{4}$ & Aprovado \\
\hline
\end{tabular}

Todos os equipamentos testados da TAB. 4 foram considerados aprovados, pois permaneceram marcando "overload" durante 5 minutos (ABNT NBR 10011, 1987) quando expostos a uma taxa 10 vezes maior que seu último fundo de escala, pois a eletrônica do detector medido altera os fundos de escala automaticamente (digital). A incerteza nas taxas de exposição não foi superior a $\pm 5 \%$.

\subsubsection{Verificação do novo sistema irradiador gama Hopewell}

Para verificar a atividade da fonte de ${ }^{137} \mathrm{Cs}$ localizada no interior do irradiador Hopewell foram realizadas medições à distância de 1 metro da fontedetector com um medidor de tipo Teletector, conforme a FIG. 33 


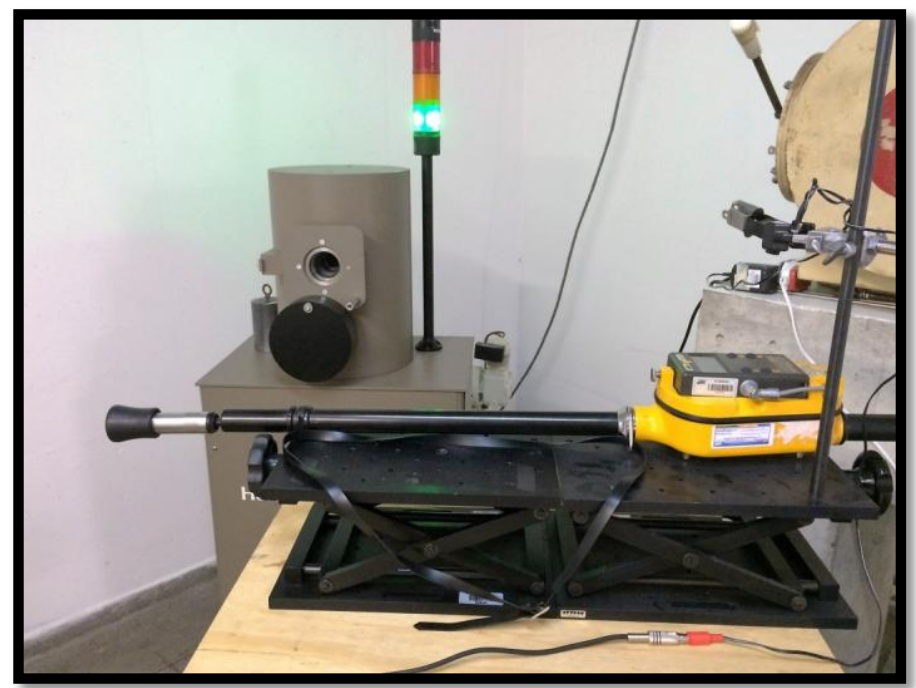

FIGURA 33. Arranjo experimental para verificar a atividade da fonte de ${ }^{137} \mathrm{Cs}$ do irradiador Hopewell.

Foram realizadas cinco medições e o valor médio da taxa de exposição com suas devidas incertezas foram de $(29,96 \pm 0,13) \mathrm{R} / \mathrm{h}$; com esse valor foram realizadas os cálculos de atividade usando a equação (6): (BITELLI, 1982; KNOLL, 2000)

$$
X=\frac{\Gamma \times A}{\mathrm{~d}^{2}} \rightarrow A=\frac{X \times d^{2}}{\Gamma}
$$

Onde:

$X=\operatorname{exposição;~}$

$A=$ atividade

$d=$ distância;

$\Gamma=$ fator gama (Fator característico da emissão gama da fonte).

Logo, substituindo os valores na equação (6), teremos: (BITELLI, 1982; KNOLL, 2000)

$$
\begin{gathered}
A=\frac{29,96 \times(1)^{2}}{0,34} \\
A=88,12 \pm 0,18[C i] \text { ou } A=3,26 \pm 0,66[\mathrm{TBq}]
\end{gathered}
$$

Valor obtido em 28/08/2015.

O valor contido no certificado de fabricação da fonte de ${ }^{137} \mathrm{Cs}(3,64 \mathrm{TBq})$ de 01/03/2014 foi assim corrigido para o dia 28/08/2015. O tempo entre o período das medições foi 545 dias ou aproximadamente 1,49 anos. Portanto, utilizando este tempo aplicado a equação (7), teremos: (BITELLI, 1982; KNOLL, 2000) 


$$
A=A_{0} \times e^{-\lambda \times t}
$$

Onde:

$A=$ atividade;

$A_{0}=$ atividade inicial;

$\lambda=$ constante de desintegração;

$t=$ tempo de decaimento do elemento.

A constante de desintegração do ${ }^{137}$ Cs é 0,02297 (KNOLL, 2000), logo:

$$
\begin{gathered}
A=3,64 \times e^{-0,02297 \times 1,49}[T B q] \\
A \cong 3,52[T B q] \text { ou } A \cong 95,13[C i]
\end{gathered}
$$

Comparando o valor medido com o valor calculado é verificada uma diferença de: (BITELLI, 1982; KNOLL, 2000)

$$
\frac{A_{\text {calc. }}}{A_{\text {med. }}}[T B q]=\frac{3,52}{3,26}=1,0797 \quad \text { ou } \cong 7,97 \%
$$

Esse valor de diferença de 7,97\% está relacionado às incertezas características do detector Teletector (Geiger Müller) e ao posicionamento do detector, pois o sistema de irradiação ainda não possuia um sistema de posicionamento de precisão e principalmente o fator de calibração foi determinado somente até metade de suas escalas, ou seja, como não foi realizada a calibração em toda sua escala de medição (até $2 \mathrm{R} / \mathrm{h}$ ) o fator de calibração não corresponde com confiabilidade para toda a escala.

\subsection{Código de conduta para utilização do Teletector}

A partir dos resultados apresentados acima neste trabalho podemos concluir que o usuário do detector de radiação ionizante de altas taxas de kerma no ar do tipo Teletector deve seguir as seguintes orientações:

Nota: estas orientações foram formadas através dos resultados apresentados nos testes de variação da leitura do equipamento com a tensão, dependência angular, dependência energética e estouro de escala ou saturação. 
- Não esperar o equipamento acusar tensão de bateria fraca. Verificar periodicamente a tensão das pilhas ou baterias do equipamento. Quando estiver com tensão inferior ao nominal realizar a troca para uma em perfeito estado.

- Ao realizar medições o volume de detecção deve ser posicionado perpendicularmente a incidência de radiação ionizante. A indicação a radiação incidente pode se alterar com a mudança de ângulo de direção formada entre o elemento detector e o feixe de radiação incidente em seu volume sensível.

- Após a realização das medições, se o usuário tiver conhecimento das características da fonte de radiação ionizante, este deve atribuir ao resultado da medição o fator de dependência energética, pois o equipamento possui dependência energética e se faz necessário a utilização do fator de correção.

- Solicitar ao laboratório que realiza calibração do equipamento, ou se o usuário tiver condições técnicas para realização do teste de estouro de escala, realiza-lo periodicamente. Obtendo assim maior segurança em verificações radiológicas de alto nível de taxa de exposição. 


\section{CONCLUSÕES}

O estudo de normas e protocolos internacionais e nacionais é muito importante para a realização de medidas com confiabilidade no campo de radiações ionizantes. A atualização e o aprimoramento contínuo se faz necessário pela complexidade de tal campo. Logo, não somente laboratórios terciários de calibração, que é o caso do LCI-IPEN, mas de usuários destes equipamentos em suas rotinas de trabalho, se faz necessário estudos, testes, e controles de qualidade dos equipamentos detectores de radiação ionizante para realização de medições com confiabilidade.

Assim, foi realizado um estudo de alternativas para realização da dosimetria dos campos de radiação ionizante utilizados para calibração de monitores portáteis, pois observou-se que o equipamento de referência do LCl não possuía confiabilidade de medição no momento dos ensaios. Realizou-se também uma nova dosimetria para fins de controle de qualidade dos feixes utilizados na própria calibração de instrumentos.

Os testes de desempenho apresentaram resultados os quais são muito importantes para caracterizar o equipamento, que neste caso é o detector modelo Automess Teletector. $O$ teste demonstrou que o equipamento possui dependência energética, pois houve uma diferença nas medições das fontes de ${ }^{60} \mathrm{Co}$ e ${ }^{137} \mathrm{Cs}$ entre $33 \%$ a $45 \%$, sendo possível observar que com leituras de ${ }^{137} \mathrm{Cs}$ as medições ficaram mais próximas do valor de referência (obtido na dosimetria do feixe), considerando as incertezas das medições.

Já as medições com a fonte de ${ }^{60} \mathrm{Co}$ ficaram fora do valor de referência, mesmo levando em conta as incertezas de medição obtidas. Logo, todos os equipamentos se apresentaram fora do recomendado pela norma (ABNT NBR 10011,1987), porém os equipamentos estavam dentro das especificações descritas pelo fabricante em seu manual, ou seja, dependência energética de \pm $50 \%$.

O teste de desempenho focando a dependência angular foi satisfatório para um ângulo não superior a $45^{\circ}$ e insatisfatório para um ângulo de $90^{\circ}$, com relação à posição de calibração, pois os valores foram maiores que $50 \%$ o que não atende ao recomendado pela norma. Logo, deve-se ter cuidado na realização das 
medições deste tipo de equipamento em suas rotinas, realizando sempre medições na referência em $0^{\circ}$, assim como apresentado neste trabalho.

No teste de variação da leitura do equipamento com a tensão das baterias todos os equipamentos obtiveram uma diferença entre $9 \%$ e $25 \%$ do valor medido com bateria com tensão nominal e tensão abaixo do valor nominal. Logo, é muito importante a verificação periódica da tensão das baterias, pois se apenas uma destas estiver com tensão inferior ao valor nominal poderá o equipamento apresentar uma diferença de até $25 \%$ no valor da medição.

$\mathrm{Na}$ verificação da atividade e valores corresponde a taxa de exposição do irradiador Hopewell foi obtido o valor de taxa de exposição de $(29,96 \pm 0,13) \mathrm{R} / \mathrm{h}$, com um erro percentual de aproximadamente $7,97 \%$ do fornecido pelo fabricante da fonte de ${ }^{137} \mathrm{Cs}$. Este erro percentual foi principalmente causado pelo método de posicionamento do detector que foi adotado, pois o sistema de irradiação ainda não possuia um sistema de posicionamento de precisão. Assim, ao se estabelecer um sistema de posicionamento de precisão foi possível realizar esta medição com mais confiabilidade e também realizar a verificação da variação da taxa de exposição pela distância, podendo enfim aplicar a calibração de medidores portáteis de alta taxa de kerma no ar neste irradiador.

Os ensaios de estouro de escala, ou saturação, são necessários para a verificação das condições de segurança dos equipamentos, pois permitem avaliar se o equipamento responde a altas taxas de exposição de forma instantânea, permitindo que o mesmo indique uma situação de anormalidade, como situação de exposição acidental do usuário a taxas de exposição excessivas, ou acima dos limites de leitura do equipamento alertando o usuário para uma situação de risco pessoal e patrimonial. É imprescindível a realização periódica deste ensaio. Os resultados dos ensaios de resposta a outras radiações ionizantes mostraram a importância de se utilizar o equipamento mais adequado para a intensidade e tipo de campo de radiação que se deseja medir.

Conclui-se que os objetivos deste trabalho foram atingidos, pois as informações obtidas permitem ao usuário e ao laboratório de calibração saberem o comportamento dos equipamentos para medição de altas taxas de exposição ou deste tipo de equipamento durante os procedimentos de calibração e em situações de rotina de uso deles e ainda em caso de emergência radiológica. 


\section{ANEXO}

\section{IPEN LCI-SP}

\section{Ensaio: Teste de Fuga de Corrente}

\section{Teste de Sensibilidade}

FM-LCl-0906-01 V01

\section{Proprietário}

Data: $\quad X X / X X / X X$

Nome: Instituto de Pesquisas Energéticas e Nucleares (IPEN).

Endereço: Av. Prof. Lineu Prestes, 2242

\begin{tabular}{|c|c|c|c|c|c|c|c|}
\hline \multicolumn{8}{|l|}{ Dosímetro } \\
\hline \multirow{5}{*}{$\begin{array}{r}\text { Eletrômetro: } \\
\text { Câmara: } \\
\text { Fonte: } \\
\text { Escala: }\end{array}$} & \multirow{4}{*}{\multicolumn{7}{|c|}{$\begin{array}{r}\text { Série: } \\
\text { Série: } \\
\text { Série: } \\
\text { Umidade Relativa: }\end{array}$}} \\
\hline & & & & & & & \\
\hline & & & & & & & \\
\hline & & & & & & & \\
\hline & $\begin{array}{l}\text { Leitura } \\
\text { (nC) }\end{array}$ & $\begin{array}{c}\begin{array}{c}\text { Fator } \\
\text { de }\end{array} \\
\text { T e p }\end{array}$ & $\begin{array}{c}\text { Tempo } \\
\text { (s) }\end{array}$ & $\begin{array}{c}\text { Temperatura } \\
\text { (ํ) }\end{array}$ & $\begin{array}{c}\text { Pressão } \\
\text { (mbar) }\end{array}$ & $\begin{array}{c}\text { Pressão } \\
\text { corr. A }\end{array}$ & $\begin{array}{l}\text { Leitura corr. } \\
\mathrm{p} / \mathrm{T} \text { e } \mathrm{p} ; \mathrm{nC}\end{array}$ \\
\hline 1 & $\mathrm{~L} 1$ & fc & 60 & $\mathrm{~T} 1$ & p 1 & $\mathrm{p} 1 \mathrm{c}$ & $(\mathrm{L} 1 / 60)^{*} \mathrm{fC}$ \\
\hline 2 & L 2 & fc & 60 & $\mathrm{~T} 2$ & $\mathrm{p} 2$ & p $1 c$ & $(\mathrm{~L} 2 / 60)^{*} \mathrm{fc}$ \\
\hline 3 & L 3 & fc & 60 & T3 & p 3 & $\mathrm{p} 1 \mathrm{c}$ & $(\mathrm{L} 3 / 60)^{*} \mathrm{fc}$ \\
\hline \multirow{2}{*}{$\begin{array}{l}4 \\
5\end{array}$} & L 4 & fc & 60 & T 4 & p 4 & p 1c & $(\mathrm{L} 4 / 60)^{*} \mathrm{fC}$ \\
\hline & L 5 & fc & 60 & $\mathrm{~T} 1$ & p 5 & $\mathrm{p} 1 \mathrm{c}$ & $(L 5 / 60)^{*} \mathrm{fC}$ \\
\hline 6 & L 6 & fc & 60 & $\mathrm{~T} 2$ & p 6 & p 1c & $(\mathrm{L} 6 / 60)^{*} \mathrm{fc}$ \\
\hline 7 & L 7 & fc & 60 & T3 & $\mathrm{p} 7$ & $\mathrm{p} 1 \mathrm{c}$ & $(L 7 / 60)^{*} \mathrm{fc}$ \\
\hline \multirow{2}{*}{$\begin{array}{l}8 \\
9\end{array}$} & L 8 & fc & 60 & $\mathrm{~T} 4$ & p 8 & p 1c & $(\mathrm{L} 8 / 60)^{*} \mathrm{fC}$ \\
\hline & L 9 & fc & 60 & $\mathrm{~T} 1$ & p 9 & p $1 c$ & $(\mathrm{~L} \mathrm{g/60})^{*} \mathrm{fC}$ \\
\hline 10 & $\mathrm{~L} 10$ & fc & 60 & $\mathrm{~T} 2$ & p 10 & $\mathrm{p} 1 \mathrm{c}$ & $(\mathrm{L} 10 / 60)^{*} \mathrm{fC}$ \\
\hline \multicolumn{2}{|c|}{ Teste de Fuga Pré } & & & & & \multicolumn{2}{|c|}{ Teste de Fuga Pós } \\
\hline Leitura (nC) & Tempo (s) & & & & & Leitura (nC) & Tempo (s) \\
\hline L 1.1 & 0 & & & & & $\mathrm{~L} 1.2$ & 600 \\
\hline L 2.1 & 600 & \multicolumn{2}{|r|}{$\frac{(\mathrm{L} 1.1-\mathrm{L} 2.1)}{600}$} & $\mathrm{nC} / \mathrm{s}$ & & L 2.2 & 1200 \\
\hline L 3.1 & 1200 & & & & & & \\
\hline & & & & & & $\frac{\mathrm{L} 1.2-\mathrm{L} 2.2}{\underline{600}}$ & $\mathrm{nC} / \mathrm{s}$ \\
\hline$\frac{\mathrm{L} 1.1-\mathrm{L} 2.1}{\underline{600}}$ & $\mathrm{nC} / \mathrm{s} \mid \mathrm{MIN}$ & e\%: & $\mathrm{MIN}^{*} 100$ & & & & \\
\hline$\frac{\mathrm{L} 1.1-\mathrm{L} 3.1}{\underline{1200}}$ & $\mathrm{nC} / \mathrm{s} \mid \mathrm{MAX}$ & e\%: & $M A X^{*} 100$ & & & & \\
\hline \multicolumn{2}{|c|}{ Media das Leituras } & & & & \multicolumn{3}{|c|}{ MÉDIA(L1 a L10) } \\
\hline \multicolumn{2}{|c|}{ Desvio Padrão } & & & & \multicolumn{3}{|c|}{ DESVPAD(L1 a L10) } \\
\hline \multicolumn{2}{|c|}{ Desvio Padrão da Média } & & & & \multicolumn{3}{|c|}{ DESVPAD / RAIZ(10) } \\
\hline \multicolumn{2}{|c|}{ Desvio Padrão Percentual } & & & & \multicolumn{3}{|c|}{ (Desvio Padrão /Média) ${ }^{*} 100$} \\
\hline \multicolumn{2}{|c|}{ Taxa de Referência $\left(T_{R}\right)$} & & & & \multicolumn{3}{|c|}{ (Fuga $\left.(\mathrm{nC} / \mathrm{min})^{*} 100\right) / 0,5$} \\
\hline
\end{tabular}




\section{Referências bibliográficas}

ABNT NBR 10011, Associação Brasileira de Normas Técnicas, Medidores e monitores portáteis de taxa de exposição de raios Xe gama, para uso em radioproteção, Rio de Janeiro, 1987.

BITELLI, T. Dosimetria e Higiene das Radiações. 1를 Edição. Editora do Grêmio Politécnico. São Paulo. 1982.

CNEN-NE-3.02, Comissão Nacional de Energia Nuclear, Serviços de Radioproteção, Rio de Janeiro, CNEN, 1998.

CNEN-NE-5.01, Comissão Nacional de Energia Nuclear, Transporte de Materiais Radioativos, Rio de Janeiro, CNEN, 1988.

CNEN-NE-6.05, Comissão Nacional de Energia Nuclear, "Gerência de Rejeitos Radioativos em Instalações Radiativas", Rio de Janeiro, CNEN, 1985.

CNEN-NN-3.01, Comissão Nacional de Energia Nuclear, Diretrizes Básicas de Proteção Radiológica. Rio de Janeiro, CNEN, 2005.

CNEN-NN-6.01, Comissão Nacional de Energia Nuclear, Requisitos para o Registro de Pessoas Físicas para o Preparo, Uso e Manuseio Fontes Radioativas, Rio de Janeiro, 1998.

DAMATTO , W. B. ; Santos, G. P.; Potiens, M. A.; Vivolo, V. Improvement of the Quality Control Programme of the Clinical Dosimeters Calibration Laboratory of the IPEN/CNENSP Using Gamma Radiation. In: International Nuclear Atlantic Conference (INAC 2013), Recife/Olinda, 2013. 
DAMATTO, W. B.; Vivolo, V., Aperfeiçoamento do Programa de Controle de Qualidade do Laboratório de Calibração de Dosímetro Clínicos do IPEN, em Feixes de Radiação Gama. Dissertação (Trabalho de conclusão de curso), IPEN/PUC-SP, 2011.

DAMATTO , W. B. ; Santos, G. P.; Potiens, M. A.; VIVOLO, V., Study of Calibration Factors $\mathrm{N}_{\mathrm{d}, \mathrm{w}}$ for Ionization Chambers Dedal with 0.60cc in Gama Radiation Beams of Co-60. In: 18th International Conference on Medical Physics (ICMP2011) e XVI Brazilian Congress of Medical Physics (XVI CBFM), Porto Alegre, 2011.

DAMATTO, W. B. ; Santos, G. P.; Potiens, M. A.; VIVOLO, V., Estudo da Corrente de Fuga, In: V Congresso Brasileiro de Metrologia, Salvador, 2009.

DAMATTO, W. B. ; Santos, G. P.; Potiens, M. A.; Vivolo, V., Estudo das Rotinas e Procedimentos de Calibração de Dosímetros Clínicos em Feixes de Radiação Gama no IPEN-CNEN/SP, In: International Nuclear Atlantic Conference INAC, Rio de Janeiro, 2009.

IAEA-TECDOC-1585, International Atomic Energy Agency, Measurement Uncertainty: A Practical Guide for Secondary Standards Dosimetry Laboratories, 2008.

ICRP, Recommendations of the International Commission on Radiological Protection. ICRP Publication 60, 1991.

ICRP, Recommendations of the International Commission on Radiological Protection. ICRP Publication 103, 2007.

IEC 395, International Electrothechnical Commission. Portable $\mathbf{X}$ and gamma radiation exposure rate meters and monitors for use in radiological protection. Geneva, 1972. 
IEC-60731, Medical Electrical Equipment Dosemeters with Ionization Chambers as Used in Radiotherapy, 1997.

ISO 4037-1, International Organization for Standardization. $\mathbf{X}$ and gamma reference radiation for calibrating dosemeters and doserate meters and for determining their response as a function of photon energy, 1996.

ISO/IEC 17025, Norma Brasileira ABNT NBR ISO/IEC 17025. Requisitos gerais para competência de laboratórios de ensaio e calibração, 2006.

KNOLL, G.F. Radiation Detection and Measurement, 3rd ed.; John Wiley \& Sons, Inc.: NY, USA, New York, 2000.

MINISTÉRIO DA SAÚDE, Portaria Federal 453. Diretrizes básicas de proteção radiológica em radiodiagnóstico médico e odontológico. Brasília: Diário Oficial da União, 1998.

OKUNO, E.; Yoshimura, E., Física das radiações, 1 edição, Ed. Oficina de Textos Brasil, São Paulo, 2010.

POTIENS, M. A. ; Vivolo , V.; Corrêa, E. L. ; Lucena, R. F. ; Dias, D. M. ; Franciscatto, P.C. ; Damatto, W.B. , Atividade em Metrologia em Radiodiagnóstico Laboratório de Calibração de Instrumentos do IPENCNEN/SP. In: I Workshop do INCT Metrologia das Radiações na Medicina, Recife, 2011.

RT-LCl-001/2011, Laboratório Nacional de Metrologia das Radiações lonizantes e Instituto de Radioproteção e Dosimetria Comissão Nacional de Energia Nuclear, Requisitos Técnicos para Certificação de Laboratórios de Calibração de Instrumentos de Medição para Radiação lonizante usados em Radioproteção, 2011. 
SANTOS, G.P., Potiens, M. P. A., Vivolo, V. Avaliação de incertezas na dosimetria de um sistema irradiador. (Uncertainties evaluation of an irradiator system dosimetry). In: RADIO2005, 2005, Rio de Janeiro. RADIO2005 (CDROM). ABENDE, 2005.

SCAFF, L. A. M.; Radiologia - Bases Físicas para Técnicos. Editora Projeto Saber. São Paulo. 2004.

SILVA, I. A., Desenvolvimento e implantação de um sistema automatizado para adequação do processo de calibração de monitores de radiação gama, Dissertação (mestrado), IPEN USP, 2012.

SRS 16 - Safety Reports Series $\mathrm{n}^{\circ} .16$, International Atomic Energy Agency.Calibration of Radiation Protection Monitoring Instruments, IAEA, Vienna, 2000.

TASIC, T., BOJKOVSKI, J., PUSNIK, I., DRNOVSEK, J, Reliability design of a calibration laboratory automation software, In Proceedings of: Conference on Precision Electromagnetic Measurements Digest, Sydney, Australia, 2002.

VIM, Vocabulário Internacional de Metrologia, Conceitos fundamentais e gerais e termos associados, $1^{\text {a }}$ edição Luso - Brasileira, 2012.

VIVOLO, V., Aplicação de Metodologia de Testes de Desempenho para Monitores Portáteis de Radiação, Dissertação (mestrado), IPEN USP, 2000. 